\title{
MULTI-FUNCTIONAL CARBON DOTS: A SYSTEMATIC OVERVIEW
}

\author{
MUTHADI RADHIKA REDDY1,2, KUMAR SHIVA GUBBIYAPPA ${ }^{1 *}$
}

1GITAM Institute of Pharmacy, GITAM Deemed to be University, Rushikonda, Visakhapatnam 530045, Andhra Pradesh, India, ${ }^{2}$ Department of Pharmaceutics, School of Pharmacy, Guru Nanak Institutions Technical Campus, Ibrahimpatnam, Hyderabad, Ranga Reddy Dist, Telangana 501506, ${ }^{*}$ School of Pharmacy, GITAM Deemed to be University, Hyderabad 502329, India Email: drgshivkumar@gmail.com

Received: 04 Feb 2021, Revised and Accepted: 20 Apr 2021

\begin{abstract}
Carbon dots (CDs) have emerged as a potential material in the multifarious fields of biomedical applications due to their numerous advantageous properties including tunable fluorescence, water solubility, biocompatibility, low toxicity, small size and ease of modification, inexpensive scale-up production, and versatile conjugation with other targeted nanoparticles. Thus, CDs became a preferable choice in various biomedical applications such as nanocarriers for drugs, therapeutic genes, photo sensitizers, unique electronic, fluorescent, photo luminescent, chemiluminescent, and electro chemiluminescent, drug/gene delivery and optoelectronics properties are what gives them potential in sensing and antibacterial molecules. Further, their potentials have also been verified in multifunctional diagnostic platforms, cellular and bacterial bio-imaging, development of nanomedicine, etc. This present review provides a concise insight into the progress and evolution in the field of carbon dots research with respect to synthesis methods and materials available in bio-imaging, theranostic, cancer, gene therapy, diagnostics, etc. Further, our discussion is extended to explore the role of CDs in nanomedicine and nano theranostic, biotherapy which is the future of biomedicine and also serves to discuss the various properties of carbon dots which allow chemotherapy and gene therapy to be safer and more target-specific, resulting in the reduction of side effects experienced by patients and also the overall increase in patient compliance and quality of life and representative studies on their activities against bacteria, fungi, and viruses reviewed and discussed. This study will thus help biomedical researchers in percuss the potential of CDs to overcome various existing technological challenges.
\end{abstract}

Keywords: Carbon dots, Sensing, Bio-imaging probes, Biotherapy, Drug delivery, Multi-drug resistance, Gene therapy

(C) 2021 The Authors. Published by Innovare Academic Sciences Pvt Ltd. This is an open access article under the CC BY license (https://creativecommons.org/licenses/by/4.0/) DOI: https://dx.doi.org/10.22159/ijap.2021v13i4.41002. Journal homepage: https://innovareacademics.in/journals/index.php/ijap

\section{INTRODUCTION}

Carbon nanodots are nano-crystals of nano materials having zero dimensions are smaller than $10 \mathrm{~nm}$ [1]. They show various size reliant optical properties such as photoluminescence, chemiluminescence, electrochemical luminescence and photoinduced electron transfer [2]. Besides, the high remarkable aqueous dispersibility, biocompatibility, good elasticity in modification, high resistance to photobleaching and chemical inertness make it well applicable in bio-imaging, bio-sensing, chemical-sensing, biomedical applications [3-8]. Being a new kind of fluorescent nanomaterial and having excellent biocompatibility, CDs are widely used in the area of bio-imaging both in vitro and in vivo and in diagnosis purposes, eco-friendliness, conductivity, desirable optical properties and low toxicity, carbon dots have revolutionized the biomedical field, in Photothermal as well as photodynamic therapy and drug/gene delivery carriers [9-11]. CDs could also be applied for the determination of cellular levels of biomolecules and ions (biosensor), such as $\mathrm{Cu}^{2+}, \mathrm{Hg}^{2+}, \mathrm{NO}^{3-}, \mathrm{C}_{6} \mathrm{H}_{12} \mathrm{O}_{6}, \mathrm{H}_{2} \mathrm{O}_{2}$, etc. CDs could also act as a promising photocatalyst after co-doping with heteroatoms, such as nitrogen, phosphorus, sulphur, and certain metal ions, such as $\mathrm{Cu}$, $\mathrm{Zn}, \mathrm{Ti}$, etc. Incorporation of these elements improves the electrondonation and acceptance ability of the CDs and promotes redox reaction on the surface of CDs [12-18]. These properties of CDs are being employed for wastewater treatment and hydrogen generation $[19,20]$. CDs are as well appropriate for surface passivation and chemical modification with several polymeric, inorganic, organic, or biological materials. The physical and fluorescence characteristics are improved by surface passivation.

In 2004, during electrophoretic purification of single-walled carbon nanotubes fluorescent carbon nanoparticles were accidentally discovered by $\mathrm{Xu}$ et al. Fluorescent-based quantum dots are of two types namely graphene quantum dots and carbon quantum dot. They make up a new class of semiconductor nano-crystals with a size range between 2 and $10 \mathrm{~nm}$ called quantum dots, and have received extensive attention due to their great potential like intrinsic photoluminescence [21]. Currently, these types of carbon dots emerged as efficient, superior and universal fluorophores, based on their characteristics, CDs have been combined with semiconductor nanoparticles such as $\mathrm{Ag}_{3} \mathrm{PO}_{4}, \mathrm{TiO}_{2}$, and $\mathrm{Fe}_{2} \mathrm{O}_{3}$ to improve their photocatalytic property [22]. These polymeric dots are cross-linked or aggregated polymer, prepared from linear monomer or polymers this type of dots is an aggregation of carbon core and connected polymer chains [23]. The three main executive parameters-the quantum confinement effects, the surface state, and the molecule state-are very important in the design of fluorescent CDs. CDs can be designed to have various functional groups including hydroxyl, carboxyl, carbonyl, ether, and epoxy in addition to their easy functionalization with amine, phosphorous, sulphur, and boroncontaining heteroatoms containing functional groups with the different organic, polymeric, and biological materials during the preparation process. Various chemical precursors have been identified as the source of CDs, such as citric acid, glycerol, l-ascorbic acid, glucose, citric acid-urea and thiourea. To convert these precursors into fluorescent CDs various synthetic processes are used, such as ultrasonication, simple heating, arc discharge, solvothermal, hydrothermal, chemical oxidation, and laser ablation [24-40]. Plentiful efforts have been made to expand the usability of CDs to fulfil the growing demand for high-performance techniques, such as bio-imaging, drug-gene delivery, chemical sensing, as well as photocatalysis and kills microorganisms.

CDs are with their effective light-harvesting over a very broad spectral range from UV to near-IR, the photoexcited CDs are capable of producing reactive oxygen species, which are known to kill/inhibit microorganisms. According to existing research results, the major processes responsible for the antimicrobial effects of CDs are likely associated with the generation of reactive oxygen species. The mechanism of action includes the adhesion of CDs to the bacterial surface, the photoinduced production of reactive oxygen species, the disruption and penetration of the bacterial cell wall/membrane, the induction of oxidative stress with damages to DNA and RNA, leading to the inhibitions of gene expressions, and the induction of oxidative damages to proteins and other intracellular biomolecules. Under visible/natural light illumination, CDs in contact with the bacteria cell can efficiently generate ROS by activating the oxygen in air or water, leading to the production of hydroxyl free radicals and singlet oxygen 
$\left(10_{2}\right)$, which can destroy some of the critical biomolecules in cell and lead to cell death [41]. However, it is also important to monitor the dimensions of CDs during its synthesis to attain uniform properties for a particular application. A large number of reports entrenched the methods of purifying the as-prepared CDs via post-treatment, for example, centrifugation, filtration, gel-electrophoresis and column chromatography. Besides, monitoring the dimensions of CDs during its formation is also preferred [44]. In this current review article, we have elucidated the novel progress of small molecule-derived CDs in the field of biomedical as well as chemical applications to date and their future perspective.

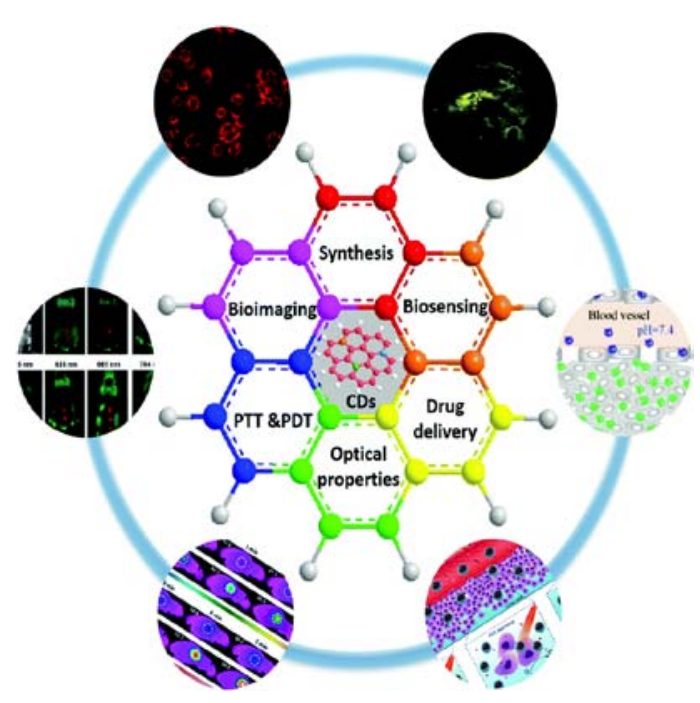

Fig. 1: Schematic illustration of the topic of this review, showing the recent trends in applications of CDs in biomedicine, including bioimaging, biosensing, and cancer therapy, [Reprinted with permission from 20, 53, 54, 74, 82 and 143. Copyright 2017 American Chemical Society, Copyright 2012 and 2018 John Wiley and Sons, Copyright 2012 and 2017 royal society of chemistry Copyright 2016 Springer]

\section{Methods of synthesis of CDs}

CDs can be synthesized mainly via two routes: (i) top-down approach and (ii) bottom-up approach. In top-down techniques, the substances mainly consisting of carbon atoms such as graphite, oxidized graphite, carbon soot, activated carbon, carbon nanotubes, etc. are subjected to relatively vigorous heating conditions, such as electrochemical exfoliation, oxidative acid treatment, laser ablation, and arc discharge, to exfoliate the bulk carbon materials into quantum dots of sizes below $10 \mathrm{~nm}$. In recent years, large-scale synthesis of high-quality CDs with controlled size distribution was achieved via an electrochemical approach using ultrapure water as a solvent, and thus electrochemical synthesis is the method of the choice for synthesizing the homogeneous morphological CDs. The homogeneousness in morphology is usually achieved by varying the applied potential at the electrode. Top-down approach refers to breaking down larger carbon structures via chemical oxidation, discharge, electrochemical oxidation, and ultrasonic methods. However, drawbacks of this approach include the requirement of expensive materials, harsh reaction conditions, and long reaction time. On the other hand, the bottom-up approach refers to the conversion of smaller carbon structures into CDs of the desired size. This bottom-up approach is consisting of hydrothermal treatment, ultrasonic treatment, thermal decomposition, pyrolysis, carbonization, microwave synthesis and solvothermal method to synthesize CDs. The syntheses of CDs through "top-down" approaches usually require a separate step for surface functionalization/passivation, but in the case of "bottom-up" approaches, no separate step is necessary, and the surface passivation can be accomplished in a one-pot synthesis. In "bottomup" approaches, small organic precursors can be polymerized and carbonized into CDs by means of hydrothermal/solvothermal synthesis, pyrolysis, microwave-assisted polymerization, and carbonization. Here this review discussed on both the top-down and bottom-up approach for the synthesis of CDs obtained from small organic molecules and with special significance on various applications and bacterial detection, the antibacterial effect of CDs. Tables 1,2,3, and 4 summarized the different synthetic methods for CDs preparation from different molecules and fig. 2 shows different synthetic methods for the preparation of CDs

\section{Top-down approach}

In the "top-down" methodology, CDs are synthesized by electrochemical oxidation, laser ablation and arc discharge method.

\section{Electrochemical method}

Electrochemical/chemical oxidation is the top-down synthetic route for the synthesis of CDs, because of several remarkable advantages, such as high yield, high purity, low cost, and easy control over size. However, tedious purification process of synthesized particles can be considered as a main disadvantage of this method. The electrochemical method is one of the most prominent methods used to synthesize ultrapure CDs from larger molecular matter like carbon nanotube, graphene, graphite, and carbon fiber by an electrolytic process where larger organic molecules are used as an electrode in the presence of proper electrolytes. Zhou et al. first reported synthesis of CDs from multiwalled carbon nanotubes in the presence of tetrabutylammonium perchlorate as electrolyte [42]. Zheng et al. synthesized water-soluble pure CDs by an electrochemical method using graphite as electrode in the presence of phosphate buffer at neutral $\mathrm{pH}$. The as-prepared CDs were successfully applied as potential biosensor [43]. Li et al. prepared crystalline CDs by an electrochemical method from graphite. The asprepared CDs exhibited size-dependent upconversion photoluminescence (PL) properties and are used in photocatalysis [44]. Later, Ray et al. used carbon soots as the carbon source for the synthesis of CDs, and this approach can be used for the mg scale synthesis of CDs [45]. Recently, CD with polyaniline hybrid was synthesized by an electrochemical technique with high QY and purity. The as-synthesized CD-polyaniline composite reported to exhibit high capacitance and used in energy-related devices. Electrochemical soaking is a powerful method to prepare CDs using various bulk carbon materials as precursors [46-50]. In another investigation, Nakamura et al. reported the fabrication of nanocrystalline CDs based on an electrochemical synthesis method [31]. They applied 1-propanol as carbon source and similar to previous works, they used two Pt electrodes along with an $\mathrm{Ag} / \mathrm{AgCl}$ electrode as a reference. The reaction was performed in a basic medium by adding of $\mathrm{KOH}$ to solution. A constant potential of $6.5 \mathrm{~V}(100 \mathrm{~mA})$ was applied to the working electrode. The obtained CDs were collected after $4.5 \mathrm{~h}$ and 7.5 $\mathrm{h}$. According to their report, both CDs produced after 4.5 and $8.5 \mathrm{~h}$ showed a similar pattern of spherical geometry with an average diameter of 3 and $4 \mathrm{~nm}$, respectively [51]. Furthermore, it was revealed that the $\mathrm{CD}$ properties significantly depended on the electrolysis time spent in the process.

\section{Chemical ablation}

Strong oxidizing acids carbonize small organic molecules to carbonaceous materials, which can be further cut into small sheets by controlled oxidation. This method may suffer from harsh conditions and drastic processes. Peng and Travas-Sejdic reported a facile aqueous solution-based procedure to produce luminescent CDs using carbohydrates as precursor materials [52]. First, they produced carbonaceous materials via dehydrating carbohydrates using concentrated sulphuric acid. Then, the obtained carbonaceous materials were treated with nitric acid and cleaved into tiny CDs. Finally, as the passivation step, a number of amino-terminated surface passivation reagents including ethylenediamine, oleylamine, bis (3aminopropyl) terminated poly (ethylene glycol) (PEG1500N) and 4,7,10-trioxa-1,13-tridecanediamine (TTDDA) were investigated. Compared to all passivized CDs, TTDDA passivized CDs showed the highest QY when excited at $360 \mathrm{~nm}$. Surface passivation was the critical step for the photoluminescence of these CDs. It was also found that prolonged nitric acid treatment resulted in a blue-shift in the 
maximum emission wavelength, possibly because of a decrement in the particle size. Nontoxic nature and multicolour emission capabilities of these CDs make them good candidates in biomedical research.

\section{Laser ablation}

The laser ablation method uses a high-energy laser pulse to irradiate the surface of the target to a thermodynamic state in which high temperature and high pressure are generated, rapidly heats up and evaporates into a plasma state, and then the vapor crystallizes to form a nanoparticle. Laser ablation is an effective method to prepare CDs with narrow size distribution, good water solubility, and fluorescence characteristics. However, its complicated operation and high cost limit its application. In laser ablation route, complex organic macromolecules are exposed under laser radiation operated in pulsed mode and nanosized carbon particles are detached from the larger molecular structures. The laser ablation technique can involve three steps: (1) the carbon materials absorb the high energy by the laser pulse; (2) electrons are stripped from the atoms through photoelectric and thermionic emission; and (3) a high electric field produces a strong repulsive force between positive ions and solid material, breaking down CDs [53]. Synthesis of CDs by a laser ablation technique was first reported by Sun et al. in 2006 from graphite powder [54]. They synthesized CDs upon laser excitation from a Nd: YAG $(1064 \mathrm{~nm}, 10 \mathrm{~Hz})$ source in an atmosphere of argon at $900^{\circ} \mathrm{C}$ and $75 \mathrm{kPa}$. Thongpool et al. synthesized CDs from bulk graphite in the presence of ethanol using a Nd: YAG laser of wavelength $1064 \mathrm{~nm}$. The synthesized CDs showed a broad absorption spectrum peaked at 325 $\mathrm{nm}$ [55]. Presently, photoluminescent CDs of $\sim 3 \mathrm{~nm}$ size have been synthesized by a laser irradiation technique from carbon glassy particles in the presence of polyethylene glycol 200. CDs so prepared are applied in bioimaging for cancer epithelial human cells [56]. Recently, Li and colleagues prepared CDs by laser ablation of a carbon target in a water vapour company with a carrier gas (argon) at $75 \mathrm{kPa}$ and $900{ }^{\circ} \mathrm{C}$. CDs with bright luminescence emission were obtained after refluxing in $\mathrm{HNO} 3$ for up to $12 \mathrm{~h}$ and passivation of the surface by organic polymers such as PEG1500N or poly propionyl ethyleneimineco-ethyleneimine (PPEI-EI) [57].

\section{Ultrasonic treatment}

Ultrasonic treatment is also a very convenient method as the large carbon materials can be broken down by the action of very high energy of ultrasonic sound wave. Wang et al. synthesized N-doped CDs from ascorbic acid and ammonia via ultrasonic treatment [58, 59]. Dang et al. fabricated CDs using oligomer-polyamide resin as the carbon source by ultrasonic treatment. The as-prepared CDs were well dispersed, had low crystallinity, and functional groups at the surface. Lu et al. reported the use of an ultrasonic-assisted, liquidphase exfoliation technique to prepare graphene carbon dots. Briefly, graphite can be well dispersed in organic solvent and the graphite layers cleave apart and are exfoliated by the surface energy for van der Waals forces of graphite layers under the ultrasonication process. This study supported that sonication can enhance the exfoliation effects and dispersion in the organic solvent [60,61].

\section{Arc discharge method}

CDs by an arc discharge method had been an accidental event. This method was first reported by Xu et al. during the synthesis of singlewalled carbon nanotubes SWCNTs [62]. Electrical discharge across two graphite electrodes results in the formation of small carbon fragment or CDs. Bottini et al. reported CDs derived from pristine and single-walled carbon nanotube by means of an arc discharge method with bright PL in the violet-blue and blue-green region, respectively [63]. Recently, Boron-and nitrogen-doped CDs were synthesized by the arc discharge method from graphite. They used $\mathrm{B}_{2} \mathrm{H}_{6}$ for doping boron and $\mathrm{NH}_{3}$ for nitrogen [64].

\section{Acid oxidizing exfoliation method}

In acid oxidizing exfoliation methods, strong acids such as $\mathrm{HNO}_{3}$, $\mathrm{H}_{2} \mathrm{SO}_{4}$, and even $\mathrm{KMnO}_{4}$ have been widely used to exfoliate CDs by the oxidation of carbon materials [65]. Hu et al. reported the oxidizing of coal with $\mathrm{H}_{2} \mathrm{O}_{2}$ to prepare $\mathrm{CDs}$ to escape the side effects of the strong acids; damage the original structure of graphitic precursors as costly purification and extreme preparation conditions with toxic chemicals.

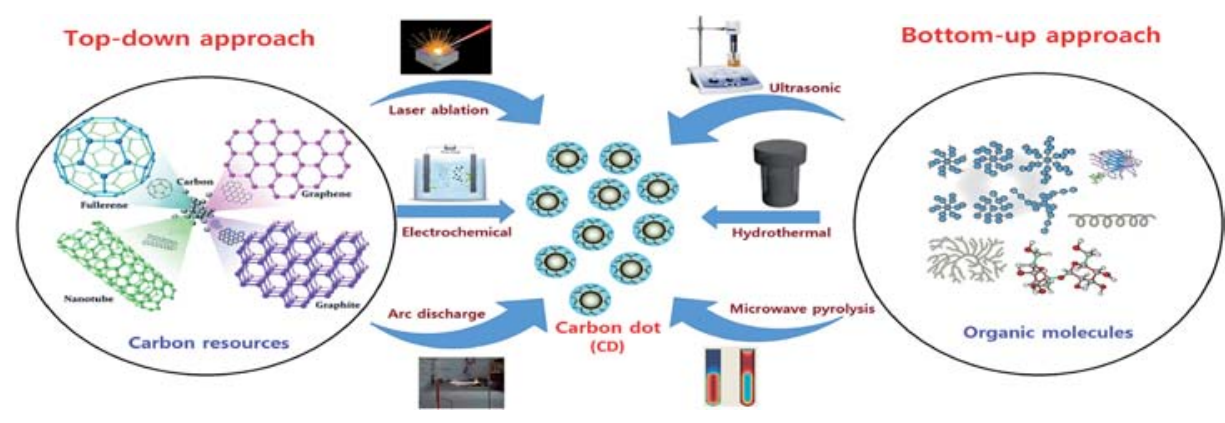

Fig. 2: Representation of the possible synthesis methods to prepare carbon dots, [Reproduced with permission from [52]. Copyright Royal Society of chemistry, 2017]

\section{Bottom-up approach}

In the bottom-up approach, CDs as bulk carbon materials are formed as the precursors change to particle forms via chemical and physical techniques, including hydrothermal, solvothermal, microwaveassisted, and thermal pyrolysis. Presently, there has been much interest in the development of bottom-up approaches for the preparation of CDs due to the precise control of precursor molecules, ease of techniques, low cost, and practicality and convenience of the procedure with generally nontoxic precursors. The features of bottom-up methods for the preparation of CDs are summarized in tables.

\section{Hydrothermal synthesis/Solvothermal treatment}

Hydrothermal synthesis method is being used by most of researchers as a cheap, eco-friendly, easy to handle and low-cost route to synthesize CDs from saccharides, amines, organic acids and their derivatives and from diverse carbon-based precursors. In this methodology, a solution of organic precursors is sealed in a hydrothermal synthetic reactor where the reaction occurs at high temperature and pressure. In a typical procedure, the precursor's usually small organic molecules are dissolved in a suitable solvent and heated to high temperatures $\left(100-200^{\circ} \mathrm{C}\right)$ in the absence of air in a Teflon-lined autoclave. The small organic moieties join together to form carbogenic cores and then grow into CDs ranging from 2 to $10 \mathrm{~nm}$ in size. Zhang et al. first reported a one-pot hydrothermal method to make CD from ascorbic acid in the presence of ethanol as solvent. QY and average particle sizes of their synthesized CDs were $6.79 \%$ and $\sim 2 \mathrm{~nm}$, respectively [67]. Pang et al. reported the synthesis of carbon doped nitrogen and sulphur in CDs (NS-CDs) derived from methionine by a hydrothermal method. Zhu et al. reported that the highest quantum as high as about $80 \%$ of CDs that is almost equal to fluorescent dyes. They used citric acid and ethylenediamine as carbon and nitrogen sources to be utilized in 
ionization to the condensation, polymerization, and carbonization steps by hydrothermal treatment at $150-300{ }^{\circ} \mathrm{C}$ for $5 \mathrm{~h}$ to prepare polymer-like and carbonaceous CDs. Even the utilization of amino acids such as serine and cystine is reported in the preparation of CDs [68].

Solvothermal carbonization followed by organic solvent extraction is a common technique to synthesize CDs. Ideally, carbon-yielding compounds were heated in a high boiling point organic solvents, this is then followed by extraction and concentration procedure. Bhunia et al. fabricated two types of CDs, hydrophilic and hydrophobic with a diameters less than $10 \mathrm{~nm}$ from carbohydrates carbonization [69]. The hydrophobic CD was produced by mixing different amounts of carbohydrate with octadecylamine and octadecene before heating to $70-300{ }^{\circ} \mathrm{C}$ for $10-30 \mathrm{~min}$. The hydrophilic ones can be produced by heating an aqueous solution of carbohydrate within wide range of $\mathrm{pH}[70]$. The hydrophilic CDs with red and yellow emissions can also be fabricated by mixing an aqueous solution of carbohydrate with concentrated phosphoric acid, then heating at $80-90{ }^{\circ} \mathrm{C}$ for $60 \mathrm{~min}$. Problems arising from CDs synthesis include;

(i) Carbonaceous aggregation during carbonization, which can be bypassed using electrochemical synthesis, solution chemist-try, or confined pyrolysis methods.

(ii) Uniformity and size control, which is crucial for uniform characteristics and mechanistic study, can be optimized through posttreatment, such as centrifugation, gel electrophoresis, and dialysis.

(iii) Surface characteristics that are crucial for solubility and selected applications, can be tuned during synthesis or posttreatment.

\section{Pyrolysis method}

Pyrolysis is a simplistic method to synthesize CDs from organic compounds by simple chemical reactions carried out at very high temperatures in the presence of strong acid or alkali. Pyrolysis is an irreversible thermal decomposition reaction in which decomposition of organic materials take place in an inert atmosphere. It involves physical as well as chemical changes in organic materials resulting in solid residue containing carbon. Generally, pyrolysis takes place at very high temperatures and under controlled pressure. Bourlinos et al. synthesized Gd (III)-doped CDs having diameter $\sim 3.2 \mathrm{~nm}$ with dual fluorescence via pyrolysis method. They prepared a mixture of tris(hydroxymethyl) aminomethane (Tris base), gadopentetic acid, and betaine hydrochloride to fabricate Gd (III)-CDs followed by the pyrolysis at $250{ }^{\circ} \mathrm{C}$ temperature [71]. Martindale et al. synthesized CDs of average diameter $\sim 6 \mathrm{~nm}$ by pyrolysis of citric acid at $180{ }^{\circ} \mathrm{C}$ for generation of hydrogen fuel-utilizing solar energy [72]. Guo et al. synthesized stable CDs from hair (keratin) by a one-step pyrolysis method at $200{ }^{\circ} \mathrm{C}$ for $24 \mathrm{~h}$ of reaction time. They successfully recovered CDs and used their CDs in the detection of $\mathrm{Hg}^{2+}$ with higher sensitivity and selectivity [73]. Recently, Rong et al. synthesized highly photoluminescent nitrogen-doped CDs (N-CDs) derived from guanidinium chloride and citric acid by a pyrolysis method and fluorescence quenching observed in the presence of $\mathrm{Fe}^{3+}$. N-CDs obtained by their synthesis were profoundly used in metal ion detections and in bioimaging [74]. Zhu et al. reported a facile microwave pyrolysis approach to synthesize CDs by combining poly (ethylene glycol) (PEG200) and a saccharide (glucose, fructose, etc.) in water to form a transparent solution, followed by heating in a microwave oven. The obtained CDs exhibited excitation-dependent photoluminescence properties. This is a simple, fast and environment-friendly preparation method for CDs rich in oxygencontaining groups [75], which would become the coordination sites of metal ions for the design of carbon-based electrocatalysts. It is of great importance to control the size during the preparation of discrete CDs with tunable and uniform sizes can be prepared via canned pyrolysis of an organic precursor in nanoreactors (fig. 3). Three steps were used as follows: (i) absorbing the organic precursor into porous nanoreactors via capillary force, (ii) pyrolysis of the organic precursor coned in the nanoreactors into carbonaceous matter, (iii) release of the as-synthesized CDs by removing the nanoreactors. The size and size distribution of the CDs produced from this method are dictated by the texture parameters of the nanoreactors.
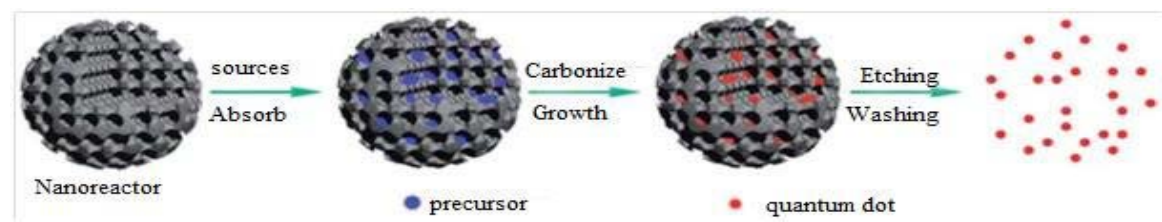

Fig. 3: Schematic illustration of the preparation of CDs via confined pyrolysis of an organic precursor in nanoreactors. [Adapted with permission.62 copyright 2012, Royal society of chemistry]

\section{Carbonization synthesis}

Carbonization of the precursor molecules is one of the best, inexpensive, simple, and ultrafast one-step methods to fabricate CDs. Carbonization is a chemical process in which solid residues with higher content of carbon are formed from organic materials by prolonged pyrolysis in an inert atmosphere. Wei et al. synthesized Ndoped CDs using this ultrafast carbonization method within two min from glucose as a carbon source, and ethylenediamine as the nitrogen source [76, 77]. The observed size of the CDs was in the range of 1 to $7 \mathrm{~nm}$ with $49 \%$ of QY.

\section{Microwave irradiation method}

Microwave-assisted synthesis is a fast, low-cost, scalable and nontoxic, energy-efficient method to synthesize CDs via the irradiation of electromagnetic radiations having a wavelength ranging from 1 $\mathrm{mm}$ to $1 \mathrm{~m}$ through the reaction mixture containing the precursor molecules. In this methodology, carbonization of the small organic molecule occurs by microwave heating within a very short period of time $[78,79]$. Zhu et al. synthesized fluorescent CDs having size $3.7 \mathrm{~nm}$ using microwave irradiation for the first time [80]. They heated the aqueous solution of saccharides and polyethylene glycol in a domestic microwave oven $(500 \mathrm{~W})$ for nearly $3 \mathrm{~min}$. Kiran et al. used citric acid as a carbon source and 3-aminophenyl boronic acidas the passivation agent to fabricate CDs. They heated the aqueous solution of citric acid, and 3-aminophenyl boronic acid in a microwave oven $(1200 \mathrm{~W})$ for $4 \mathrm{~min}$ and the average diameter of the obtained CDs was ranging from 2 to $5 \mathrm{~nm}$ [81]. Recently Cao et al. synthesized CDs from the aqueous solution of glucose and arginine using microwave-assisted pyrolysis in a microwave oven $(700 \mathrm{~W})$ for near about $10 \mathrm{~min}$. The average diameter of the as-obtained CDs was between 1 and $7 \mathrm{~nm}$ [82]. Using sucrose as the carbon source and diethylene glycol as the reaction media, green luminescent CDs were obtained within one minute under microwave irradiation. These DEGstabilized CDs could be well-dispersed in water with a transparent appearance. With an increase in the excitation wavelength, the intensity of the PL first increased to a maximum ( $360 \mathrm{~nm}$ ) excitation) and then decreased. However, no perceptible shift of the PL peak over an excitation range from 320 to $380 \mathrm{~nm}$ could be observed. Moreover, these DEG-CDs could be efficiently ingested by C6 glioma cells and exhibited low cytotoxicity, suggesting their potential in bioimaging. Liu et al. promoted microwave-mediated pyrolysis of citric acid with various amine molecules to synthesize highly luminescent CDs. Several other researchers have also reported the microwave-assisted synthesis of CDs.

\section{Thermal decomposition}

This method offers various advantages, such as easy to operate, less time consuming, low cost, and large-scale production. In thermal 
decomposition, a substance or compound decomposes chemically by the action of heat. Thermal decomposition reactions are generally endothermic. This type of decomposition reactions are either irreversible (decomposition of starch, proteins) or reversible (decomposition of ammonium chloride, limestone) [83]. Wang et al. synthesized CDs by this method from citric acid. They heated citric acid on a hot plate at $200{ }^{\circ} \mathrm{C}$ for $30 \mathrm{~min}$; neutralized with sodium hydroxide solution, and finally dialyzed for purification. The size of
CDs was observed within the range from 0.7 to $1 \mathrm{~nm}$ [84]. These CDs showed both excitation-dependent as well as independent photoluminescent properties, and different QY depending on different synthesis conditions. Wan et al. used the thermal decomposition of 1-butyl 3-methyl imidazolium bromide and 1cysteine for the synthesis of $\mathrm{CDs}$ at $240{ }^{\circ} \mathrm{C}$ [85]. Some other researchers also reported the synthesis of $\mathrm{CDs}$ from small organic molecules via this method.

Table 1: Synthesis of CDs from small organic molecule via top-down approach

\begin{tabular}{|c|c|c|c|c|c|c|}
\hline $\begin{array}{l}\text { S. } \\
\text { No. }\end{array}$ & Source & Method of preparation & $\begin{array}{l}\text { Doping }(d) / \text { surface } \\
\text { passivating (p) agents }\end{array}$ & Color & Size (nm) & Ref. \\
\hline 1. & Carbon soot & Chemical oxidation & - & Green & $2-5$ & [123] \\
\hline 2. & Oligomer polyamide resin & Ultrasonic treatment & Silane Coupling agent (p) & Bright white & $2-4$ & [126] \\
\hline 3. & Graphite powder & Laser ablation & - & Red, black, and blue & $1.5,1.6$ and 1.8 & [128] \\
\hline 4. & Carbohydrates & Chemical oxidation & $\begin{array}{l}\text { (TTDDA) 4,7,10-trioxa- } \\
\text { 1,13-tridecanediamine (P) }\end{array}$ & $\begin{array}{l}\text { Red, blue, green, } \\
\text { and yellow }\end{array}$ & 5 & [130] \\
\hline 5. & Carbon nanotube & Electrochemical synthesis & - & Blue & $2.8 \pm 0.5$ & [132] \\
\hline 6. & Tolune & Laser ablation & - & $\begin{array}{l}\text { Red, black and } \\
\text { blue }\end{array}$ & $\begin{array}{l}2-3.9,3-10.0,10- \\
17.2 \text { and } 13-20.5\end{array}$ & [125] \\
\hline 7. & Graphite electrode & Electrochemical synthesis & - & Bright yellow & $4 \pm 0.2$ & [131] \\
\hline 8. & Sodium citrate and urea & Electrochemical synthesis & - & Blue & $1.0-3.5$ & [127] \\
\hline 9. & $\begin{array}{l}\text { Low molecular-weight } \\
\text { alcohols }\end{array}$ & Electrochemical synthesis & - & Red and Blue & $\begin{array}{l}2.1,2.9,3.5 \text { and } \\
4.3\end{array}$ & [129] \\
\hline 10. & $\begin{array}{l}\text { Ascorbic acid and } \\
\text { ammonia }\end{array}$ & Ultrasonic treatment & Silane Coupling agent (p) & Bright blue & $2-4$ & [124] \\
\hline
\end{tabular}

Table 2: Synthesis of CDs from small organic molecule via hydrothermal treatment

\begin{tabular}{|c|c|c|c|c|c|c|}
\hline $\begin{array}{l}\text { S. } \\
\text { No. }\end{array}$ & Source & Method of preparation & $\begin{array}{l}\text { Doping (d) surface } \\
\text { passivating (p) agent }\end{array}$ & Color & $\begin{array}{l}\text { Size } \\
(\mathrm{nm})\end{array}$ & Ref. \\
\hline 1. & Dopamine & Hydrothermal Treatment & 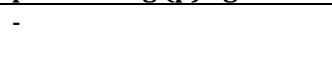 & $\begin{array}{l}\text { Blue, yellow, } \\
\text { green }\end{array}$ & 3.8 & [133] \\
\hline 2. & Streptomycin & Hydrothermal Treatment & - & Violet & 2.97 & [138] \\
\hline 3. & Sodium citrate & Hydrothermal Treatment & - & Blue & 1.59 & [141] \\
\hline 4. & Glucosamine HCL & Hydrothermal Treatment & Glucosamine HCL (d) & Green & $15-70$ & [146] \\
\hline 5. & Glucose, monopotassium phosphate & Hydrothermal Treatment & - & Violet & $1.83-3.83$ & [146] \\
\hline 6. & Citric acid and ethylene diamine & Hydrothermal Treatment & - & Blue & $2-6$ & [135] \\
\hline 7. & Histidine, $\mathrm{NAOH}$ & Hydrothermal Treatment & - & Blue & $3-5$ & [151] \\
\hline 8. & bPEL, ammonium persulfate & Hydrothermal Treatment & bPEL & Blue & $3-4$ & [144] \\
\hline 9. & Ammoinum citrate, ethylenediamine & Hydrothermal Treatment & $N(d)$ & Blue & 4.8 & [153] \\
\hline 10. & Citric acid & Hydrothermal Treatment & Isoleucine (d) & Violet & $6-15$ & [152] \\
\hline 11. & L-Serine, L-Cystine & Hydrothermal Treatment & $\mathrm{N}, \mathrm{S}(\mathrm{d})$ & Orange & 2.6 & [148] \\
\hline 12. & Ammonium citrate & Hydrothermal Treatment & Ethylene diamine (d) & Indigo & 4.8 & [142] \\
\hline 13. & 1-Octadecane 1-hexadecylamine & Hydrothermal Treatment & Dihydrolipoic acid (P) & Yellow & $6-8$ & [136] \\
\hline 14. & Citric acid, ethanediamine & Hydrothermal Treatment & - & Violet & $<5$ & [137] \\
\hline 15. & Citric acid, GSH & Hydrothermal Treatment & - & Blue & $2.5-3$ & [140] \\
\hline 16. & Citric acid, NAOH & Hydrothermal Treatment & - & Green & 11.3 & [147] \\
\hline 17. & Folic acid, Phosphoric acid & Hydrothermal Treatment & Folic acid, Phosphoric acid (d) & Indigo & $13.2 \pm 1.6$ & [140] \\
\hline 18. & Citric acid, $\mathrm{NH}_{3} \cdot \mathrm{H}_{2} \mathrm{O}$ & Hydrothermal Treatment & $N(d)$ & Blue & 2 & [145] \\
\hline 19. & Glucose & Hydrothermal Treatment & - & Blue & 1.65 & [149] \\
\hline 20. & Sodium nitrate, histidine & Hydrothermal Treatment & - & Indigo & 1.5 & [143] \\
\hline 21. & L-Phenylalaninol & Hydrothermal Treatment & - & Violet & 2.8 & [139] \\
\hline 22. & $\begin{array}{l}\text { APTS (3-Aminopropyl) } \\
\text { (Triethoxysilane), Glycerol }\end{array}$ & Hydrothermal Treatment & - & Violet & $9 \pm 0.5$ & [150] \\
\hline
\end{tabular}

\section{Applications of CDs}

\section{Gene and biomedicine/drug delivery}

CDs have been micro-sized, they are readily available for cell uptake and more biocompatible to reduce cytotoxic effects, thus, they are likely to be safe, potent, and good delivery vectors and nanostructured materials in conjugate with the drug(s) can improve the drug delivery systems with respect to the drugs absorption, distribution and elimination. Currently, CDs have received increasing attention for drug delivery due to their superior properties such as fluorescence emission, and resultant cell membrane permeability, low toxicity, chemical inertness, water-solubility, easy synthesis, potential functionalization, and drug loading. Several researchers have applied CDs in drug delivery systems. For example, Wang et al. synthesized doxorubicin (DOX)-loaded CDs, which showed potential for application in both cell imaging and cancer therapy [86]. Initially, they prepared hollow CDs from bovine serum albumin by solvothermal reaction $(6.8 \mathrm{~nm}$ in diameter, pore size of $2 \mathrm{~nm}$ and $\mathrm{QY}=7.5 \%)$ and then the produced particles were loaded with DOX. The sonicated solution of BSA $(10 \mathrm{mg})$, ultrapure water $(5 \mathrm{ml})$ and ethanol $(10 \mathrm{ml})$ was heated at $180{ }^{\circ} \mathrm{C}$ for $12 \mathrm{~h}$ and then cooled to room temperature. Hollow CDs were centrifuged $(10,000 \mathrm{rpm})$ and then added to DOX ( $0.1 \mathrm{mg} \mathrm{ml}^{-1}$ ) and stirred for a couple of hours for loading of DOX into Hollow CDs. Fluorescence images of A549 cells confirmed that hollow CDs could be internalized by A549 cells and were mainly localized in the cytoplasm but could not enter the nucleus. Cell viability and cellular uptake results suggest that the Hollow CDs show low toxicity and act as a potential platform in drug delivery field. pH-triggered drug release, rapid cellular uptake, excitation-dependent and excellent biocompatibility were reported as the prominent advantages of designed HCDs-based drug delivery system [87]. Thakur et al. reported designing of antibiotic-conjugated CDs via a microwave- 
assisted method using gum arabic as the precursor, which used a theranostic agent for controlled drug release, bioimaging and enhanced antimicrobial activity. In this work, CDs served as a carrier for ciprofloxacin hydrochloride, a broad-spectrum antibiotic, which was attached to the surface of synthesized CDs. The Cipro carbon dots showed good biocompatibility on Vero cells as compared to free ciprofloxacin $(1.2 \mathrm{mmol})$ and ciprofloxacin release from CDs depended extremely on physiological conditions. These CDs exhibited improved antimicrobial effect against both gram-negative $(E$. coli) and grampositive ( $S$. aureus) microorganisms and also showed bright green fluorescent when live imaging was applied to view yeast cells under the fluorescent microscope and also give an effective new nanocarrier for controlled drug release with a high antimicrobial activity under physiological conditions [88].

Table 3: Synthesis of CDs from small organic molecules via decomposition, carbonization, pyrolysis, solvothermal, and Ultrasonic treatment

\begin{tabular}{|c|c|c|c|c|c|c|}
\hline $\begin{array}{l}\text { S. } \\
\text { No. }\end{array}$ & Source & Method of preparation & $\begin{array}{l}\text { Doping }(d) \text { surface } \\
\text { passivating }(p) \text { agent }\end{array}$ & Color & $\begin{array}{l}\text { Size } \\
(\mathrm{nm})\end{array}$ & Ref. \\
\hline 1. & $\mathrm{CCl}_{4}, \mathrm{NANH}_{2}$ & Solvothermal treatment & $\mathrm{N}(\mathrm{d})$ & $\begin{array}{l}\text { Blue, Cyan, Kelly, } \\
\text { and yellow }\end{array}$ & 3.3 & [154] \\
\hline 2. & Hydroquinone & Solvothermal method & $\mathrm{BBR}_{3}(\mathrm{~d})$ & Blue & 16 & [144] \\
\hline 3. & $\mathrm{Sicl}_{4}$, Hydroquinone & Solvothermal method & $\mathrm{Si}(\mathrm{d})$ & Blue & $7 \pm 2$ & [125] \\
\hline 4. & Glucose, $\mathrm{HCl} / \mathrm{NaOH}$ & Ultrasonic treatment & - & Blue & $<5$ & [160] \\
\hline 5. & Active carbon, $\mathrm{H}_{2} \mathrm{O}_{2}$ & Ultrasonic treatment & - & $\begin{array}{l}\text { Blue, green, } \\
\text { yellow, red }\end{array}$ & $5-10$ & [157] \\
\hline 6. & Glucose & Carbonization & $\begin{array}{l}\text { Ethylene diamine }(d) \text {, } \\
\text { phosphoric acid }(p)\end{array}$ & Green & $1-7$ & [162] \\
\hline 7. & Citric acid & Carbonization & - & Blue & $4.8-9$ & [164] \\
\hline 8. & 6-0-(0-0-dilauroyl-tartaryl)-D-glucose & Carbonization & Green & Green & $2.4 \pm 0.5$ & [147] \\
\hline 9. & Tris base, betaine $\mathrm{Hcl}$ & Pyrolysis & Gadopetetic acid (d) & Purple, Green & 3.2 & [161] \\
\hline 10. & GDs & Pyrolysis & L-glutamic acid & $\begin{array}{l}\text { Blue, green and } \\
\text { red }\end{array}$ & $4.66-1.24$ & [165] \\
\hline 11. & D-Glucose & Pyrolysis & L-Aspartic acid (d) & Yellow & $2.28 \pm 0.42$ & [159] \\
\hline 12. & Sodium alginate & Pyrolysis & - & Blue & $<10$ & [144] \\
\hline 13. & Citric acid & Pyrolysis & Diethylenetriamine (p) & Indigo & $5-8$ & [155] \\
\hline 14. & $\begin{array}{l}\text { Citric acid, } N-(\beta \text {-Aminoethyl)- } \gamma- \\
\text { aminopropyl methyl dimethoxy silane }\end{array}$ & Thermal decomposition & AEAPMS (p) & Blue & 0.9 & [124] \\
\hline 15. & Citric acid & Thermal decomposition & $\operatorname{DETA}(p)$ & Blue & $3-5.5$ & [138] \\
\hline 16. & Citric acid & Thermal decomposition & Ruthenium (III) & Blue & $6.8 \pm 2.3$ & [156] \\
\hline 17. & Citric acid & Thermal decomposition & - & Blue & $0.7-1.0$ & [163] \\
\hline 18. & Citric acid & Thermal treatment & Dicyanamide (d) & Green & $8-16$ & [158] \\
\hline 19. & L-Cystein & Thermal Decomposition & $\begin{array}{l}\text { 1-butyl 3-methyl } \\
\text { imidazolium bromide }\end{array}$ & $\begin{array}{l}\text { Blue, yellow, red, } \\
\text { green }\end{array}$ & $1.0-3.5$ & [150] \\
\hline
\end{tabular}

Table 4: Synthesis of CDs from small organic molecule via microwave treatment

\begin{tabular}{|c|c|c|c|c|c|c|}
\hline S. No. & Source & $\begin{array}{l}\text { Method of } \\
\text { preparation }\end{array}$ & $\begin{array}{l}\text { Doping }(d) \text { surface } \\
\text { passivating }(p) \text { agent }\end{array}$ & Color & $\begin{array}{l}\text { Size } \\
(\mathrm{nm})\end{array}$ & $\begin{array}{l}\text { Refs. } \\
\text { No. }\end{array}$ \\
\hline 1. & Glycerol & Microwave synthesis & PEI $(d, p)$ & Blue & $9 \pm 1.1$ & {$[155]$} \\
\hline 2. & Citric acid Urea & $\begin{array}{l}\text { Microwave-assisted } \\
\text { synthesis }\end{array}$ & - & Green & $2-6$ & [166] \\
\hline 3. & Arginine and glucose & Microwave synthesis & - & Blue & $1-7$ & [169] \\
\hline 4. & Triammonium Citrate & Microwave synthesis & - & Indigo & 6.6 & [171] \\
\hline 5. & Citric acid & Microwave synthesis & Tryptophan (d) & Indigo & 2.6 & [167] \\
\hline 6. & Glycerol & Microwave synthesis & TTDA (p) & $\begin{array}{l}\text { Blue, turquoise, green, } \\
\text { jacinth, and red }\end{array}$ & 5 & [134] \\
\hline 7. & Saccharides and polyethylene glycol & Microwave synthesis & - & Blue & 3.7 & [164] \\
\hline 8. & Carbohydrates and inorganic salts & Microwave synthesis & - & Blue, green, yellow & 2.1 & [152] \\
\hline 9. & Citric acid & Microwave synthesis & RNase A (d) & Blue & $25-45$ & [168] \\
\hline 10. & Citric acid & Microwave synthesis & Boric acid (d) & Indigo & $2-6$ & [170] \\
\hline 11. & Citric acid & Microwae synthesis & $\begin{array}{l}\text { 3-Aminophenyl } \\
\text { boronic acid (d) }\end{array}$ & Indigo & $2-5$ & [164] \\
\hline
\end{tabular}

Cationic CDs have shown great potential as gene carriers and delivery applications because of their ability of electrostatic interaction with positively charged functionalized CDs and negatively charged nucleic acids. Cao et al. prepared positively charged CDs from porphyra polysaccharide and ethylenediamine precursors with a high QY of $57.3 \%$ to induce the neuronal differentiation of adult stem cells through nonviral gene deliver [89]. Gene transfection is faster and more efficient in neuronal induction from the adult stem cells by using these plasmid DNA-loaded CDs that can be used in bioimaging, gene delivery, and tissue engineering. Yang et al. reported turn on-off theranostic fluorescent CDs against hyaluronidase (HAase) in cancer cells for self-targeted imaging and drug delivery. Negatively charged CDs were modified with cationic polyethyleneimine (PEI) through electrostatic interaction to prepare P-CDs and functionalized with hyaluronic acid-Doxorubicin conjugate (P-CDs/HA-Dox) and these nanoprobe can pass into the cells readily with targeting specify to the CD44 receptor on the cancer cell. HA can be degraded to tetra saccharide units in the presence of the HAase enzyme [90]. Therefore, Dox can be released from a P-CDs/HA-Dox nanoprobe into cancer cells because of the enzyme-triggered drug delivery and induce apoptosis in Hela cancer cells. Therefore, this study clearly showed that CDs can be successfully used in the targeted bioimaging and delivery vehicles for image-guided chemotherapy. Tables 5 and 6 summarized some of the methods for the delivery of QDs.

CDs is a carbon material attracting tremendous interest in distinct fields of biomedicine. A facile and green synthesis of DNA-CDs using 
genomic DNA isolated from Escherichia coli has been reported. The DNA-CDs were purified by column centrifugation-based technique. During the course of the formation of DNA-CDs, it was assumed that nitrogen is released by the thermal degradation of ribose which resulted in the formation of several new bonds $(\mathrm{C}-\mathrm{OH}, \mathrm{N}-\mathrm{O}$, and $\mathrm{N}-\mathrm{P})$ where many covalent bonds of the DNA were retained. The presence of ample amino and hydroxyl groups enables further functionalization.
The remarkable biocompatibility warranted the DNA-CDs to be used in the design of novel type of fluorescent probes for bioimaging and drug delivery and CDs synthesized from carbon nano powder have high binding affinity to calcified bones in vivo with specificity [91, 92], and the bone-binding ability of the CDs was not significantly altered by surface passivation, which demonstrated the promising applications of CDs as highly bone-specific bioimaging agents and drug carriers.

Table 5: Methods used for the delivery of carbon dots

\begin{tabular}{|c|c|c|c|c|c|}
\hline S. No. & Strategy & Mode of action & Examples & Targeted cells & Refs \\
\hline \multirow[t]{11}{*}{1.} & Facilitated & Peptide-mediated & Histidine-Arginine-rich peptide gH625 & A549(lung adenocarcinomal cytosol) & {$[172]$} \\
\hline & delivery & & (Herps simplex virus derived-peptide) & HeLa (cervical adenocarcinoma; cytosol & \\
\hline & & & JB577 peptide (palmitoylated) & $\begin{array}{l}\text { HEK, COS-1, A549, primary fibroblast, chick } \\
\text { embryo, rat hippocampal neurons(cytosol) }\end{array}$ & [176] \\
\hline & & & LAH, sweet arrow peptide & COS-1 (African green monkey kidney) & [181] \\
\hline & & & Chemoseletive Peptides & A549 & [179] \\
\hline & & & Chitosan & L929 (murine fibrosarcoma) & {$[174]$} \\
\hline & & & Liposomes & B16F10 (mouse melanoma) & [178] \\
\hline & & Polymers & Triblock copolymers & Panc-1 & [183] \\
\hline & & Small molecule & Lactose & $\begin{array}{l}\text { Hela, Araki Sasaki (human corneal } \\
\text { epithelium) }\end{array}$ & [182] \\
\hline & & & Galactose & HepG2 (Hepatocyte), MCF-7 & {$[175]$} \\
\hline & & & Gambogic acid & HepG2 & [173] \\
\hline \multirow[t]{6}{*}{2.} & Active & Nanoneedle Injection & & HeLa & [177] \\
\hline & Delivery & Reversible membrane & & Rat cardiomyocyte (H9C2) & [180] \\
\hline & & Permeabilization & & & \\
\hline & & $\begin{array}{l}\text { Nanochannel } \\
\text { electroporation }\end{array}$ & & A549 & [173] \\
\hline & & Nanoblade & & HeLa & [177] \\
\hline & & $\begin{array}{l}\text { Microfluidic cell } \\
\text { 'squeezing' }\end{array}$ & & HeLa & [173] \\
\hline 3. & $\begin{array}{l}\text { Passive } \\
\text { uptake }\end{array}$ & $\begin{array}{l}\text { QD surface } \\
\text { character/chaarge }\end{array}$ & & Human primary epithelial & [180] \\
\hline
\end{tabular}

Table 6: A summary on CD use in drug delivery

\begin{tabular}{|c|c|c|c|c|c|}
\hline $\begin{array}{l}\text { S. } \\
\text { No. }\end{array}$ & Source of CD & Drug/Method & $\begin{array}{l}\text { Disease/Model } \\
\text { system }\end{array}$ & Efficiency & $\begin{array}{l}\text { Reference } \\
\text { number }\end{array}$ \\
\hline 1. & $\begin{array}{l}\text { FA-Gd CD green CDs synthesized from } \\
\text { crab shell doped with } \mathrm{Gd}^{+} \text {and conjugated } \\
\text { with folic acid }\end{array}$ & $\begin{array}{l}\text { Targeted drug delivery of } \\
\text { doxorubicin }\end{array}$ & HeLa cell line & $\begin{array}{l}\text { Significantly higher to toxicity } \\
\text { towards HeLa cells and less } \\
\text { toxicity in vivo (zebrafish } \\
\text { embryos and other cell lines) }\end{array}$ & [185] \\
\hline 2. & $\begin{array}{l}\text { MSN-SS-CD }{ }_{\text {PAA }}-D O X \text { CQD synthesized by } \\
\text { hydrothermal polymerization method } \\
\text { using poly-acrylic acid }\end{array}$ & $\begin{array}{l}\text { Multifunctional } \\
\text { nanosystem (targeted and } \\
\text { controlled delivery of drug } \\
\text { doxorubicin along with } \\
\text { bioimaging }\end{array}$ & $\begin{array}{l}\text { In vitro (human } \\
\text { prostrate cancer cell } \\
\text { line) }\end{array}$ & $\begin{array}{l}\text { High therapeutic effect } \\
\text { against cancers and good } \\
\text { biocompatibility and stability } \\
\text { silica particles containing the } \\
\text { drug doxorubicin }\end{array}$ & [185] \\
\hline 3. & CQD (Nitric acid oxidation of candle soot) & Phototherapy & Cell line & $\begin{array}{l}\text { Higley cytotoxic to cancer } \\
\text { cells }\end{array}$ & [188] \\
\hline 4. & $\begin{array}{l}\text { CQD hydrothermal treatment of citric } \\
\text { acid, hyaluronic and ethylenediamine }\end{array}$ & 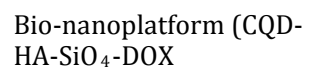 & Cancer cell line & Low cytotoxicity & [191] \\
\hline 5. & $\begin{array}{l}\text { MSN-SS-CDHA-DOX CQD synthesized by } \\
\text { decomposition of citric acid and conjugated } \\
\text { with HA, which were further mesoporous } \\
\text { silica nanoparticles enclosing the anti- } \\
\text { tumor drug, doxorubicin }\end{array}$ & $\begin{array}{l}\text { Multifunctional } \\
\text { nanosystem (targeted } \\
\text { and controlled drug } \\
\text { delivery of doxorubicin } \\
\text { along with bioimaging) }\end{array}$ & In vivo mouse model & $\begin{array}{l}\text { High therapeutic efficiency } \\
\text { towards cancer cells }\end{array}$ & [187] \\
\hline 6. & $\begin{array}{l}\text { CQD-Asp (Thermolysis of d-glucose and } \\
1 \text {-aspartic acid }\end{array}$ & - & $\begin{array}{l}\text { In vivo mouse model } \\
\text { of brain tumor }\end{array}$ & $\begin{array}{l}\text { High biocompatibility and } \\
\text { less toxicity }\end{array}$ & [193] \\
\hline 7. & $\begin{array}{l}\text { CQD (hydrothermal treatment of citric } \\
\text { acid monohydrate, with diethylene glycol } \\
\text { bis ether) }\end{array}$ & - & $\begin{array}{l}\text { Both in vitroandin } \\
\text { vivo model of glioma } \\
\text { (brain cancer) }\end{array}$ & $\begin{array}{l}\text { Successful targeting of } \\
\text { glioma }\end{array}$ & [190] \\
\hline 8. & $\begin{array}{l}\text { CQDs Pt(IV)@PEG-(PAH/DMMA) } \\
\text { CQD, prepared by thermal pyrolysis of citric } \\
\text { acid, conjugated with PEG-(PAH/DMMA) }\end{array}$ & Cisplatin & $\begin{array}{l}\text { Both in vitroandin } \\
\text { vivo model }\end{array}$ & $\begin{array}{l}\text { High tumor inhibition } \\
\text { efficiency and low side } \\
\text { effects }\end{array}$ & [184] \\
\hline 9. & $\begin{array}{l}\text { CQD-PEG-Ag acid oxidation of carbon } \\
\text { nanotube and graphite }\end{array}$ & Radiotherapy & Cell lines & Cytotoxic to cancer cells & [189] \\
\hline 10. & $\begin{array}{l}\text { mPEG-OAL-DOX/CQD (CQD, prepared by } \\
\text { pyrolysis of citric acid, cross-linked with } \\
\text { PEGylated oxidized alginate (mPEG-OAL) }\end{array}$ & Doxorubicin & In vitro cell model & $\begin{array}{l}\text { Cytotoxic specifically to } \\
\text { cancer cells }\end{array}$ & [186] \\
\hline 11. & $\begin{array}{l}\text { CQDs Microwave synthesis method using } \\
\text { acrylic acid and ethylene diamine } \\
\text { followed by functionalization with } \\
\text { glycidyl methacrylate }\end{array}$ & $\begin{array}{l}\text { Targeted cancer drug } \\
\text { delivery }\end{array}$ & $\begin{array}{l}\text { Nanogel } \\
\text { (copoymerized with } \\
\text { zwitterionic amini } \\
\text { acid ornithine } \\
\text { methacrylamide) }\end{array}$ & Low cytotoxicity & [192] \\
\hline
\end{tabular}


Table 7: Role of CDs in gene delivery system

\begin{tabular}{|c|c|c|c|c|c|}
\hline S. No. & Source molecule & Ligand attached & $\begin{array}{l}\text { Drug/gene } \\
\text { delivery }\end{array}$ & Cell type & $\begin{array}{l}\text { Refs. } \\
\text { No. }\end{array}$ \\
\hline 1. & Sorbitol and sodium hydroxide & Folic acid & DOX & HeLa & [196] \\
\hline 2. & EDTA & $\begin{array}{l}\text { Mesoporous silica } \\
\text { nanoparticles (MSPs) }\end{array}$ & DOX & HeLa & [199] \\
\hline 3. & $\begin{array}{l}\beta \text {-Cyclodextrin }(\beta C D) \text {, oligoethylenimine } \\
(\mathrm{OEI}) \text { and Phosphoric acid }\end{array}$ & $\mathrm{OEI} / \mathrm{CD}$ & DOX & H1299 & [194] \\
\hline 4. & $\begin{array}{l}\text { Polyethyleneimine and fluorinated } \\
\text { diglycidyl ethers }\end{array}$ & Flourine doped & siRNA/DNA & HeLa cells & [202] \\
\hline 5. & Citric acid and tryptophan & PEI & siRNA & MGC-803 & [197] \\
\hline 6. & Citric acid and Polyene polyamine & - & Oxaliplatin & Hepatic cancer cells & [204] \\
\hline 7. & Glycerol and polyethyleneimine & $\begin{array}{l}\text { Fc-rPEI(folate conjugated } \\
\text { reducible PEI rPEI) }\end{array}$ & SiRNA & $\mathrm{H} 460$ & [194] \\
\hline 8. & Arginine and glucose & - & pSOX-9 & $\begin{array}{l}\text { Chondrogenic differentiation of } \\
\text { mouse embryogenic Fibroblasts }\end{array}$ & [200] \\
\hline 9. & $\begin{array}{l}\text { ATP (Adenosine Triphosphate) moreover, } \\
\text { polyethyleneimine (PEI) }\end{array}$ & Hyaluronic acid (HA) & DOX & HeLa cells & [198] \\
\hline 10. & Urea and citric acid & Carboxyl groups on CDs & DOX & HepG2 and HL-7702 & [203] \\
\hline 11. & D-Glucose $(2.5 \mathrm{mmol})$ and L-glutamic acid & Polydopamine coated & DOX & HeLa cells & [195] \\
\hline 12. & Carbon nanopowder & Transferrin & DOX & $\begin{array}{l}\text { Glioblastoma cells; CHLA-266, } \\
\text { DAOY,CHLA-200 and SJGBM2 cells }\end{array}$ & [205] \\
\hline 13. & $\begin{array}{l}\text { Branched polyethyleneimine, Hyaluronic } \\
\text { acid }\end{array}$ & $\begin{array}{l}\text { Hyaluronate (HA) and } \\
\text { polyethyleneimine (PEI) }\end{array}$ & DNA/RNA & HeLa Cells & [201] \\
\hline 14. & Citric acid and o-phenylenediamine & - & DOX & $\begin{array}{l}\text { HeLa, mouse fibroblast cells } \\
\text { (L929) }\end{array}$ & [198] \\
\hline
\end{tabular}

\section{Bioimaging}

CDs have similar remarkable fluorescent properties but extremely low cytotoxicity, which makes them strong candidates to be used to design novel bioimaging probes. The researcher also selected the blue luminescent $\mathrm{N}-\mathrm{CD}$ s to incubate with a human cervical cancer cell line for $2 \mathrm{~h}$ under different channels, clearly visualized the fluorescent imaging of HeLa cells. As a control, the HeLa cells untreated with NCDs did not show any fluorescence. To confirm the potential application of $\mathrm{S}, \mathrm{N}-\mathrm{CDs}$ as a bioimaging probe, and also conducted in vitro cellular uptake experiments in MCF-7 cells, which was recorded by laser scanning confocal microscopy [93-95]. Polythiophene phenyl propionic acid-derived red-emissive CDs were synthesized by Ge et al. and used for both in vitro and in vivo imaging [96]. For in vitro bioimaging, HeLa cells were treated with the CDs which showed red fluorescence localized in the cytoplasm when excited at $542 \mathrm{~nm}$. They also intravenously injected CDs in the HeLa-tumor-bearing mice and observed that the CDs were mostly accumulated inside the tumor due to enhanced permeation and retention effect. The various bioimaging applications are summarised in table 8.

Table 8: Role of CDs in bioimaging applications

\begin{tabular}{|c|c|c|c|c|}
\hline S. No. & Source molecule & Color & Application (bio-imaging) & Refs. No. \\
\hline 1. & Glycine & Green & MCF-7 cell & [208] \\
\hline 2. & Glycerol solvent & Blue & HeLa Cell & {$[215]$} \\
\hline 3. & Carbon soot & Blue-yellow & HepG2 cell & {$[215]$} \\
\hline 4. & Activated carbon & Blue/yellow/green & COS-7cells & [211] \\
\hline 5. & Graphene oxide and ammonia & Green & HeLa Cells & [217] \\
\hline 6. & Glucose TTDDA & Green & HeLa, MCF-7, NH-3T3 cells & [207] \\
\hline 7. & Citric acid and ethylenediamine & Blue & MC3T3 cell & [219] \\
\hline 8. & Sucrose and oil acid & Green & 16HBE CELL & {$[212]$} \\
\hline 9. & $\begin{array}{l}\text { Graphene oxide and } \\
\text { Dimethylformamide }\end{array}$ & Green & HeLa Cells & [221] \\
\hline 10. & Graphite Powder & Green/Blue & A549 cell & [209] \\
\hline 11. & Polycyclic aromatic hydrocarbon & Green & MCF-7 cell & [219] \\
\hline 12. & Folic acid & Blue/Green & U87glioma cell & [213] \\
\hline 13. & Citric acid, PEG diamine, and Glycerin & Blue & Cholesterol imaging & [216] \\
\hline 14. & Urea, polyethylene glycol & Blue & L929 cells & [220] \\
\hline 15. & Citric acid, urea, and sodium fluoride & Red & Glioma C6 cells & [207] \\
\hline 16. & $\begin{array}{l}\text { Citric acid, phosphoric acid, and } \\
\text { ethylene diamine }\end{array}$ & Red, green & $\begin{array}{l}\text { Raw } 2647 \text { cells, PA and FL } \\
\text { imaging of mice tumors }\end{array}$ & [223] \\
\hline 17. & Glycerol polyethyleneimine & Blue/green/red & COS-7 cell & [212] \\
\hline 18. & CX-72 carbon black & Green & MCF-7 cell & [225] \\
\hline 19. & Graphite rods and hydrazine & Yellow & $\begin{array}{l}\text { Neutrospheres cells, pancreas progenitor cells, and } \\
\text { cardiac progenitor cells were performed }\end{array}$ & [206] \\
\hline 20. & Carbon nanotubes and graphite & Yellow & In vivo NIR fluorescence imaging in mice & {$[222]$} \\
\hline 21. & Carbon fibers & Green & 147D Cell & [218] \\
\hline 22. & Glucose, monopotassium phosphate & Green & HepG2 cell & [227] \\
\hline 23. & Graphene oxide and DMF & Green & MG-63 cell & [210] \\
\hline 24. & Carbon soot & Blue-yellow & HepG2cell & {$[224]$} \\
\hline 25. & Activated carbon & Blue/yellow/green & $\cos -7$ & {$[214]$} \\
\hline 26. & Citric acid, AEAPMS and silica & Blue & BGC823 cell & [226] \\
\hline
\end{tabular}




\section{Sensor and biosensors}

Fluorescence CDs can be used as sensors for the detection and identification of a wide range of analytes, that is, cations, anions, drugs, small molecules, and macromolecules, depending on high sensitivity and selectivity, and the easy operation as benign biocompatible, and low-cost device applications. There are three main strategies to design CDs as a sensor material: As the prepared CDs interact with the analyte, the fluorescence signals could be changed; Specific receptors or special functional groups can be conjugated via post-modification on CDs to generate sensing ability; and Quenchers, fluorophores, and substrates integrations of CDs could be used as sensory materials [97-99]. The functional groups on the surface can be interacted with several metal ions such as $\mathrm{Ag}^{+}$, $\mathrm{Au}^{3+}, \mathrm{Fe}^{3+}, \mathrm{Cr}^{3+}, \mathrm{Cu}^{2+}, \mathrm{Eu}^{2+}, \mathrm{As}^{3+}, \mathrm{Hg}^{2+}, \mathrm{Pb}^{2+}, \mathrm{Sn}^{2+}, \mathrm{Co}^{2+}$, and their binary and ternary mixtures with nonspecific sensing $[101,102]$. The types of precursors and their surface state can be designated the quenching responsive of CDs to specific analytes.

Atashi et al. also demonstrated the same "on-off-on" fluorescent using $\mathrm{Cu}^{2+}$ and D-penicillamine. It is obvious that these studies clearly reveal that the fluorescent effects of CDs from chitin nanofibers was quenched or "turned off" after the addition of $\mathrm{Cu}^{2+}$ ions, whereas the fluorescent was "turned on" again in the presence of $\mathrm{D}$-penicillamine as the $\mathrm{Cu}^{2+}$ ions were bound to $\mathrm{D}$ penicillamine instead of CDs with high affinity [103-105]. Therefore, using a specific ligand and competitive binding interaction can be used in the design of very specific sensors for biomedical and environmental applications. The utilization of CDs as biosensing devices to recognize specific biological molecules such as glucose, amino acids, peptides, nucleotides, proteins, DNA, vitamins, cells, and bacteria has attracted great attention, especially for clinical sample analysis, early diagnosis of sickness, and so on. For example, the glucose level in the human body is of vital importance for the treatment of diabetes and/or cancerous diseases [97]. Moreover, Li et al. showed the biosensing effects of mannose-modified CDs against bacteria labelling by high selectivity of the CDs that bind to a specific lectin unit of the filegalle of the wild type E. coli K12 strain. In addition, these CDs can be successfully used in the labelling of bacteria by the fluorescence detection method in the real samples, including tap water, apple juice, and human urine [107]. Residue corresponding to antibiotics was determined by a CD-based composite sensor where either PL quenching (turn off) or enhancement (turn on) was observed. Antibiotics or their residues like tetracycline, cephalexin, ciprofloxacin, norfloxacin, oxytetracycline, and chlortetracycline have been detected from raw milk, egg, meat, and human urine sample. Estrogen drugs those were used in animals, birds, for fast growth can also be traced out by CD-based sensor very effectively [108-113]. Consequently, the utilization of different CDs in the recognition of different biomolecules is a viable procedure and offers a great advantage over the common diagnostic procedures in many aspects in biomedical applications summarised in table 9, 10 and also discussed in this review.

Table 9: Role of CDs in bio-sensing application

\begin{tabular}{|c|c|c|c|c|}
\hline S. No. & Precursor molecule & Color & Application (bio-sensing) & Ref. \\
\hline 1. & Oxalic acid (OA) and urea & Blue & $\mathrm{Fe}^{3+}$ and $\mathrm{Ag}^{+}$ & {$[331]$} \\
\hline 2. & Fullerenes (C60) & Blue & $\mathrm{Fe}^{3+}$ & [229] \\
\hline 3. & $\mathrm{SiCl}_{4}$ hydroquinone & Blue & $\mathrm{Fe}^{3+}, \mathrm{H}_{2} \mathrm{O}_{2}$ and melamine & [331] \\
\hline 4. & Lactose and $\mathrm{NAOH}$ & Blue & Folic acid & [333] \\
\hline 5. & Citric acid, aminoguanidine & Blue & Nitric oxide (NO) & [333] \\
\hline 6. & Galactose and $m$-aminophenyl boronic acid & Blue & Galactose & [335] \\
\hline 7. & L-Glutamic acid & Blue, green, red & $\mathrm{H}_{2} \mathrm{O}_{2}$ & [228] \\
\hline 8. & Citric acid and melamine & Blue & Glutathione & [332] \\
\hline 9. & $\mathrm{BBr}_{3}$, hydroquinone & Blue & $\mathrm{H}_{2} \mathrm{O}_{2}$, and glucose & [334] \\
\hline 10. & Dopamine and (3-aminopropyl) triethoxysilane, glycerol & Blue & $\mathrm{Ag}^{+}$ & [330] \\
\hline
\end{tabular}

Table 10: Role of CDs in chemical-sensing application

\begin{tabular}{|c|c|c|c|}
\hline S. No. & Precursor molecule & Application (chemical-sensing & Ref. \\
\hline 1. & Sodium citrate and citric acid & $\mathrm{Hg}^{+}$ & [341] \\
\hline 2. & Citric acid, $\mathrm{NH}_{3} . \mathrm{H}_{2} \mathrm{O}$ & $\mathrm{Hg}^{+}$ & [346] \\
\hline 3. & Ammonium citrate and ethylenediamine & $\mathrm{Hg}^{+}$ & [338] \\
\hline 4. & Sodium citrate and citric acid & $\mathrm{Hg}^{+}$ & [344] \\
\hline 5. & Ethylenediaminetetra acetic acid (EDTA) & $\mathrm{Hg}^{+}$ & [351] \\
\hline 6. & Folic acid and 3-aminopropyl trimethoxy silane & $\mathrm{Fe}^{+}$ & [340] \\
\hline 7. & Cetylpyridinium bromide (CPB) & $\mathrm{Fe}^{+}$ & [356] \\
\hline 8. & Citric acid & $\mathrm{Fe}^{+}$ & [358] \\
\hline 9. & Citric, thiourea & $\mathrm{Fe}^{+}$ & [343] \\
\hline 10. & Ethylene glycol & $\mathrm{Fe}^{+}$ & [352] \\
\hline 11. & Polycyclic aromatic hydrocarbon (PAH) & $\mathrm{Fe}^{+}$ & [347] \\
\hline 12. & Graphite rods & $\mathrm{Fe}^{+}$ & [353] \\
\hline 13. & Phenolphthalein and ethylenediamine & $\mathrm{Hg}^{+}$, lemon yellow dye, $\mathrm{Fe}^{2+}$ and $\mathrm{H}_{2} \mathrm{O}_{2}$ & [359] \\
\hline 14. & Phenylenediamine & $\mathrm{Fe}^{+}$ & [337] \\
\hline 15. & D-sorbitol & $\mathrm{Fe}^{+}$ & [348] \\
\hline 16. & Citric acid & $\mathrm{Fe}^{+}$, and $\mathrm{I}^{+}$ & [357] \\
\hline 17. & Uric acid & $\mathrm{Ag}^{+}$and $\mathrm{Hg}^{2+}$ & [336] \\
\hline 18. & $\mathrm{CCl}_{4}$ as a carbon and diamines as nitrogen precursors & $\mathrm{Ag}^{+}$ & [350] \\
\hline 19. & Citric acid and amino acid & $\mathrm{Ag}^{+}$ & [338] \\
\hline 20. & 1,2 diaminobenzene & $\mathrm{Ag}^{+}$ & [345] \\
\hline 21. & Uric acids & $\mathrm{Ag}^{+}$ & [340] \\
\hline 22. & Urea, polyethylene glycol & $\mathrm{Ag}^{+}$ & [345] \\
\hline 23. & Citric acid and guanidine thiocyanate & $\mathrm{Ag}^{+}$ & [351] \\
\hline 24. & Citric acid, polyethyleneimine for BPEI-CQDs & $\mathrm{Cu}^{2+}$ & [341] \\
\hline 25. & Citric acid & Selenite $\left(\mathrm{SeO}_{3}{ }^{2-}\right)$ & [331] \\
\hline 26. & Ammonium citrate and ethylenediamine & $\mathrm{I}^{-}$ & [342] \\
\hline 27. & Citric acid, and 1,6,-diaminohexane hydrochloride & $\mathrm{Cr}^{+}$ & [349] \\
\hline 28. & Sodium alginate & Ascorbic acid & [345] \\
\hline
\end{tabular}




\section{Electrocatalytic/energy}

CDs have been used in energy conversion and storage as well as electrocatalytic and photocatalytic devices, owing to their outstanding features such as low cost, broad optical absorbance, high photo and chemical stability, environmental friendless and nontoxicity, and scalable synthesis methods. Hu et al. reported $\mathrm{ZnO}$ nanorodefunctionalized CDs (ZnO@CDs) as an energy conversion and storage material in photoelectrochemical (PEC) water splitting from solar to hydrogen energy conversion.ZnO@CDs as a photoanode enhanced the Photo-electrochemical activity compared with the bare $\mathrm{ZnO}$ nanorodes for solar water splitting, due to the extended-spectrum response range improving the photo conversion efficiency. This study cornered out that functionalization of the $\mathrm{CD}$ surfaces with photosensitive materials can improve the photo-electrochemical activity for solar conversion [114]. The various applications are summarised in table 11.

Table 11: Role of CDs in electrocatalytic application

\begin{tabular}{|c|c|c|c|c|}
\hline S. No. & Nanomaterial & Source molecule & Photocatalysis applicaaation/role of support & $\begin{array}{l}\text { Ref. } \\
\text { No. }\end{array}$ \\
\hline 1. & $\begin{array}{l}\mathrm{N} \text { doped GDs- } \mathrm{ZnNb}{ }_{2} \mathrm{O}_{6} / \mathrm{g}-\mathrm{C}_{3} \mathrm{~N}_{4} \\
\text { hetero structures }\end{array}$ & $\begin{array}{l}\text { Urea for g- } \mathrm{C}_{3} \mathrm{~N}_{4} \text { and } \mathrm{C}_{6} \mathrm{H}_{5} \mathrm{O}_{7}\left(\mathrm{NH}_{4}\right)_{3} \text {, } \\
\text { NAOH for NGDs }\end{array}$ & $\mathrm{H}_{2}$ generation & [345] \\
\hline 2. & CDs & Citric acid & $\mathrm{H}_{2}$ generation & [368] \\
\hline 3. & $\mathrm{CDs} / \mathrm{TiO}_{2}$ & Vitamin C & $\mathrm{H}_{2}$ generation & [346] \\
\hline 4. & $\mathrm{CDs} / \mathrm{TiO}_{2}$ & Graphite & $\mathrm{H}_{2}$ generation & [367] \\
\hline 5. & $\begin{array}{l}\text { PEG } 1500 N \text {-functionalized CDs } \\
\text { with } \mathrm{Au} / \mathrm{Pt} \text { doping }\end{array}$ & Carbon-based & $\mathrm{H}_{2}$ generation and $\mathrm{CO}_{2}$ Photoreduction & [346] \\
\hline 6. & Au-doped CDs & Carbon-based & $\mathrm{CO}_{2}$ Photoreduction & [348] \\
\hline 7. & $\mathrm{~g}-\mathrm{C}_{3} \mathrm{~N}_{4}$ & Urea or melamine & Conversion of $\mathrm{CO}_{2}$ into methanol & [351] \\
\hline 8. & Reduced graphene oxide/ZnO & Graphene Oxide & $\mathrm{CO}_{2}$ Photoreduction & [354] \\
\hline 9. & $\mathrm{CDs} / \mathrm{la}_{2} \mathrm{Ti}_{2} \mathrm{O}_{7}$ & Vitamine $\mathrm{C}$ and ethanol & Rhodamine B (RhB) & [364] \\
\hline 10. & $\begin{array}{l}\text { Ultrafine amorphous iron } \\
\text { oxyhydroxide/ultrathin } \mathrm{g}-\mathrm{C}_{3} \mathrm{~N}_{4}\end{array}$ & Urea & $\begin{array}{l}\text { Degradation of Rhodamine B, methylene blue, and } \\
\text { methyl orange }\end{array}$ & [361] \\
\hline 11. & $\mathrm{CDs} / \mathrm{Bi}_{2} \mathrm{O} 3$ & L-Ascorbic acid & Degradation of Rhodamine $b$ & [360] \\
\hline 12. & $\mathrm{~S}, \mathrm{~N}$ doped GDs/g- $\mathrm{C}_{3} \mathrm{~N}_{4}$ & Citric acid and thio urea & Rhodamine B (RhB) degradation & [356] \\
\hline 13. & $\mathrm{CDs} / \mathrm{g}-\mathrm{C}_{3} \mathrm{~N}_{4}$ & Citric acid, ethylenediamine & $\begin{array}{l}\text { Degradation of Rhodamine B and tetracycline } \\
\text { hydrochloride (TC-HCl) }\end{array}$ & [349] \\
\hline 14. & $\mathrm{CDs} / \mathrm{Ag} / \mathrm{Ag}_{2} \mathrm{O}$ & Glucose & Rhodamine b & [353] \\
\hline 15. & $\mathrm{~S}, \mathrm{~N}$ doped $\mathrm{GDs} / \mathrm{TiO}_{2}$ & $\begin{array}{l}\text { Citric acid for c-dots and } \\
\text { urea/thiourea for N, S }\end{array}$ & Degradation of Rhodamine B & [358] \\
\hline 16. & $\mathrm{CDs} / \mathrm{g}-\mathrm{C}_{3} \mathrm{~N}_{4} / \mathrm{MoO}_{3}$ & Citric acid, urea and dicyandiamide & Degradation of tetracycline (TC) & [365] \\
\hline 17. & $\mathrm{Ag}-\mathrm{CDs} / \mathrm{g}-\mathrm{C}_{3} \mathrm{~N}_{4}$ & Citric acid, ethylenediamine & Naproxcen & [362] \\
\hline 18. & $\mathrm{~Pb}-\mathrm{CDs}-\mathrm{TiO}_{2}$ & Ascorbic acid and kollicoat & Degradation of RBX,CRB, and CNB dye & [366] \\
\hline 19. & $\mathrm{CDs} / \mathrm{ZnFe}_{2} \mathrm{O}_{4}$ & $\begin{array}{l}\text { L-Ascorbic acid, glycol and deionized } \\
\text { water }\end{array}$ & NO removal & [347] \\
\hline 20. & $\mathrm{CDs} / \mathrm{Bi}_{2} \mathrm{WO}_{6}$ & Citric acid, ethylenediamine & Degradation of methyl orange and bisphenol A & {$[352]$} \\
\hline 21. & $\begin{array}{l}\text { Ultrafine amorphous iron } \\
\text { oxyhydroxide/ultrathin g-C3N4 } \\
\text { nanosheets }\end{array}$ & Urea & Methyl Orange & [361] \\
\hline 22. & $\mathrm{~N}$ doped CDs & Glucose and ammonia & Photodegradation of methyl orange & [350] \\
\hline 23. & $\mathrm{La} / \mathrm{Cu} / \mathrm{Zr} / \mathrm{CDs}$ & D-Fructose, $\mathrm{NaOH}$ & Degradation of ampicillin antibiotic, malachite green & [355] \\
\hline 24. & CDs/nitrogen-doped $\mathrm{ZnO}$ & Carbon black pigment & Degradation malachite green & [357] \\
\hline 25. & $\mathrm{Fe}(\mathrm{III}) / \mathrm{CDs}$ & $\begin{array}{l}\text { Oxidative coupling of Xylene by } \\
\text { anhydrous } \mathrm{FeCl}_{3}\end{array}$ & $\mathrm{H}_{2} \mathrm{O}_{2}$ reduction & [363] \\
\hline 26. & $\mathrm{~N}$ doped $\mathrm{CDs} / \mathrm{TiO}_{2}$ & Glycerol and TTDDA & Degradation of methylene blue & [359] \\
\hline
\end{tabular}

\section{Biomedicine delivery system}

It is an attractive prospect to combine medical therapy and bioimaging diagnostics for visual drug distribution and monitoring of their effects. A multifunctional theranostic agent (CD-Oxa) was prepared by the conjugation of an anticancer agent (oxidized oxaliplatin, oxa(IV)-COOH) onto the surface of $\mathrm{CDs}$ containing amine groups. CD-Oxa successfully integrates the optical properties of the CDs and the therapeutic performance of Oxa. The in vitro results indicated that CD-Oxa possesses good biocompatibility, bioimaging function, and anticancer effects. The in vivo results demonstrate that it is possible to follow the track or distribution of the drug by monitoring the fluorescence signal of CD-Oxa, which helps customize the injection time and dosage of the medicine (fig. 5)

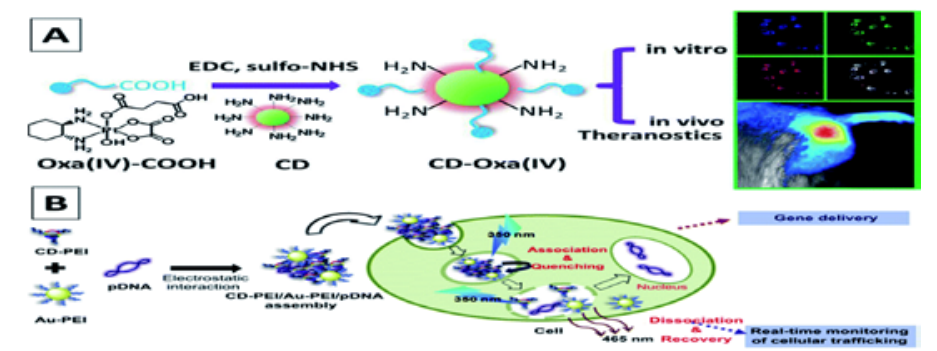

Fig. 5: Synthetic scheme for CD-Oxa and its applications in bioimaging and theranostics, [Adapted with permission.53 Copyright 2014, Wiley-VCH. (B) A schematic illustration for the gene delivery and real-time monitoring of cellular trafficking utilizing CD-PEI/AuPEI/pDNA assembled nanohybrids. Adapted with permission.112 Copyright 2013, Elsevier] 


\section{Anti-fungi/Anti-viral effects}

The fortuitous discovery of CDs concerted efforts have been devoted to discover novel nanomaterial-based strategy for combating the infectious disease with high selectivity/specificity to overcome multidrug-resistant bacterial infection. The recent studies have proved that the doping of commonly used antibiotics, e. g., ciprofloxacin on CDs' surface remarkably increases the selectivity and specificity of the antibiotics which makes the CDs an efficient platform to construct a novel drug delivery system and enhance the efficacy/selectivity of the existing antibacterial agents [115]. Yang et al. synthesized of a novel kind of CDs using glycerol as a carbon source and 3-[2-[2 aminoethylamino) ethylamino]propyl-trimethoxysilane as a surface passivating agent $[116,117]$. The as-synthesized CDs showed the capabilities of selective recognition of Gram-positive bacteria and remarkable antibacterial activity. Recently, Huang, et al. found that CDs synthesized from benzoxazine monomer could block the infection of life-threatening flaviviruses (Japanese encephalitis, Zika, and dengue viruses) and non-enveloped viruses (porcine parvovirus and adenovirus-associated virus) in vitro, probably via directly binding to the surface of the virion and eventually impeding the first step of virus-cell interaction [118]. There have been a few reported on the anti-fungi activities of CDs are shown in table 12 is a brief summary of CDs samples and their various antimicrobial uses.

Table 12: Summary of carbon dots samples and their antimicrobial actions/results

\begin{tabular}{|c|c|c|c|c|}
\hline CDs configuration & $\begin{array}{l}\text { Light } \\
\text { activation }\end{array}$ & Microorganism & Highlight of antimicrobial action & Refs. \\
\hline $\begin{array}{l}\text { Dot sample from Carbonization } \\
\text { synthesis coupled with ampicillin }\end{array}$ & Visible light & E. Coli & $\begin{array}{l}\text { The MIC value decreased to } 14 \mu \mathrm{g} / \mathrm{ml} \text { from free } \\
\text { ampicillin of } 25 \mu \mathrm{g} / \mathrm{ml}\end{array}$ & {$[360]$} \\
\hline Dot sample carrying penicillin & Visible light & $\begin{array}{l}\text { S. aureus, E. coli }(\mathrm{DH} 5 \alpha) \text {, } \\
\text { MDR E. coli, MRSA }\end{array}$ & $\begin{array}{l}\text { The treatment at } 100 \mu \mathrm{g} / \mathrm{ml} \text {, inhibited more than } 50 \% \\
\text { Of MDR E. coli and MRSA }\end{array}$ & [368] \\
\hline $\begin{array}{l}\text { Dot sample from carbonization in } \\
\text { polymer films }\end{array}$ & Blue Light & $\begin{array}{l}\text { S. aureus, E. coli, } \\
\text { K. pneumoniae }\end{array}$ & $\begin{array}{l}\text { Light irradiation for } 60 \text { min caused up to } 5 \text { logs of } \\
\text { inhibition effects }\end{array}$ & [366] \\
\hline Dot sample with $\mathrm{Na}_{2} \mathrm{~W}_{4} \mathrm{O}_{13} / \mathrm{WO}_{3}$ & Visible light & E. coli & $\begin{array}{l}\text { The treatment for } 100 \text { min inactivated about } 2 \times 10^{7} \\
\text { CFU/ml, of E. Coli, cells }\end{array}$ & {$[370]$} \\
\hline $\begin{array}{l}\text { Dot sample from Carbonization } \\
\text { synthesis coupled with } \mathrm{ZnO} \text { in } \\
\text { hydrogel }\end{array}$ & $\begin{array}{l}660 \mathrm{~nm} \text { and } \\
808 \mathrm{~nm} \text { light }\end{array}$ & S. aureus, E. coli & $\begin{array}{l}\text { With the dual-light irradiation, inactivated } 99.9 \% \text { of } \\
\text { the bacteria }\end{array}$ & [362] \\
\hline $\begin{array}{l}\text { Dot sample from electrochemical } \\
\text { processing of carbon rod and } \\
\text { then coupled with } \mathrm{TiO}_{2}\end{array}$ & Visible light & S. aureus, E. coli & $\begin{array}{l}\text { The treatment at } 1 \mathrm{mg} / \mathrm{ml} \text { for } 1 \mathrm{~h} \text { reduced }>7 \text { logs and } \\
1.82 \text { logs viable cells, respectively }\end{array}$ & [364] \\
\hline $\begin{array}{l}\text { Dot sample from carbon nano } \\
\text { powders combined with } \mathrm{H}_{2} \mathrm{O}_{2}\end{array}$ & White light & E. coli & $\begin{array}{l}\text { A mixture of } 10 \mu \mathrm{g} / \mathrm{ml} \text { dots and } 8.82 \mathrm{mmol} \mathrm{H}_{2} \mathrm{O}_{2} \\
\text { reduced } 2.46 \text { logs of viable cells }\end{array}$ & [371] \\
\hline $\begin{array}{l}\text { EDA-CDs, EPA-CDs, PEI } 600-\mathrm{CDs} \\
\text { and } \mathrm{PEI}_{1200}-\mathrm{CDs} \text { (all from } \\
\text { functionalization of CNP) }\end{array}$ & Visible light & B. Subtilis & $\begin{array}{l}\text { EDA-CDs treatment at } 0.1 \mathrm{mg} / \mathrm{ml} \text { for } 1 \mathrm{~h} \text { reduced } 3.26 \\
\text { logs of viable cells, while EPA-CDs treatment barely } \\
\text { showed any reduction. } \\
\text { PEI } 600 \text {-CDs and } \text { PEI }_{1200} \text {-CDs treatment at } 0.1 \mathrm{mg} / \mathrm{ml} \text { for } \\
1 \mathrm{~h} \text { reduced }>7 \text { logs and } 1.82 \text { logs viable cells, respectively. }\end{array}$ & [374] \\
\hline $\begin{array}{l}\text { EDA-CDs (from chemical } \\
\text { functionalization of CNPs) }\end{array}$ & Visible light & S. aureus, E. coli & $\begin{array}{l}\text { EDA-CDs treatment for } 30 \text { min reduced } \sim 4 \text { logs } E \text {. coli } \\
\text { viable cell numbers }\end{array}$ & [363] \\
\hline $\begin{array}{l}\text { EDA-CDs, EPA-CDs (both from } \\
\text { chemical functionalization of } \\
\text { CNPs) }\end{array}$ & - & $\begin{array}{l}\text { Human noroviruses } \\
\text { virus-like particles } \\
\text { (VLPs) }\end{array}$ & $\begin{array}{l}\text { EDA-CDs and EPA-CDs at } 5 \mu \mathrm{g} / \mathrm{ml} \text { inhibited } 100 \% \text { and } \\
85-99 \% \text {, of the binding of VLP to histo-blood group } \\
\text { antigens receptors on human cells. }\end{array}$ & [375] \\
\hline $\begin{array}{l}\text { Dot sample made from } \\
\text { benzoxazine monomer }\end{array}$ & - & $\begin{array}{l}\text { Japanese encephalitis, } \\
\text { Zika and dengue viruses, } \\
\text { and porcine parvovirus } \\
\text { and adenovirus- } \\
\text { associated viruses }\end{array}$ & $\begin{array}{l}\text { The dots could directly bind to the surface of the } \\
\text { virion, and } 95 \text { eventually impede the first step of virus- } \\
\text { cell interaction }\end{array}$ & [377] \\
\hline Dot sample made from vitamin $C$ & - & $\begin{array}{l}\text { R. Solani and P. grisea } \\
\text { fungi }\end{array}$ & $\begin{array}{l}\text { The treatment at } 300 \mu \mathrm{g} / \mathrm{ml} \text { significantly inhabited the } \\
\text { growth of the fungi }\end{array}$ & {$[373]$} \\
\hline $\begin{array}{l}\text { Dot sample carrying ciprofloxacin } \\
\text { hydrochloride }\end{array}$ & & S. aureus, E. coli & The MIC value lower for, E. coli than that for $E$. coli & [376] \\
\hline $\begin{array}{l}\text { Dot sample from carbonization } \\
\text { synthesis doped with } \mathrm{Au}\end{array}$ & - & C. albicans fungus & Antifungal activity with $\mathrm{MIC}_{80} \sim 250 \mu \mathrm{g} / \mathrm{ml}$ & [361] \\
\hline $\begin{array}{l}\text { Dot sample carrying } \\
\text { metronidazole }\end{array}$ & - & P. gingivalis & Only selectively inhibiting obligate anaerobes & [372] \\
\hline $\begin{array}{l}\text { Dot sample from PEG-diamine } \\
\text { and ascorbic acid as a precursor }\end{array}$ & - & $\begin{array}{l}\text { Pseudorabies virus, porcine } \\
\text { reproductive and respiratory } \\
\text { syndrome virus }\end{array}$ & Significantly inhibited the multiplication of the viruses & [365] \\
\hline $\begin{array}{l}\text { Dot sample from carbonization } \\
\text { synthesis carrying quaternary } \\
\text { ammonium moieties }\end{array}$ & - & S. aureus & $\begin{array}{l}\text { Killing the Gram-positive bacteria and also staining the } \\
\text { dead cells for fluorescent analysis }\end{array}$ & {$[366]$} \\
\hline $\begin{array}{l}\text { Dot sample from carbonization of } \\
\text { ammonium citric coupled with } \\
\text { spermidine }\end{array}$ & - & P. aeruginosa, MRSA & $\begin{array}{l}\text { Antibacterial activities against all of the tested } \\
\text { bacteria. }\end{array}$ & [369] \\
\hline
\end{tabular}

\section{Photothermal therapy (PTT)}

CDs with idiosyncratic optical properties, robust stability, and remarkable biocompatibility are of significant importance manifesting potential applications in bioimaging and PTT of various kinds of carcinomas [119]. Yang et al. used dopamine as a carbon source to synthesize CDs via a facile hydrothermal process. The as- synthesized CDs was subjected to in vitro PTT study after irradiation with an $808 \mathrm{~nm}$ laser (1.5W cm-2); 100\% tumor cell eradication was reported with no serious side effects to the normal tissues [120]. Moreover, Wang et al. reported novel self-assembled redemissive CDs@Au nanoflowers were fabricated and demonstrated efficient photothermal properties under $750 \mathrm{~nm}$ laser irradiation, and fluorescence imaging abilities [121,122]. 


\section{Photodynamic therapy (PDT)}

Carbon dots in photodynamic therapy (PDT) Photodynamic therapy (PDT) offers low toxicity, minimal invasiveness, and targeted therapy towards cancer. It comprises three main factors, a light source, a photosensitizer, and a radical. Here, a laser excites the photosensitizer to generate reactive oxygen that eventually destroys the cancer cells shown in fig. 6. CDs are shown in table 13 is a brief summary of CDs samples and their various photo-dynamic and photothermal therapy.

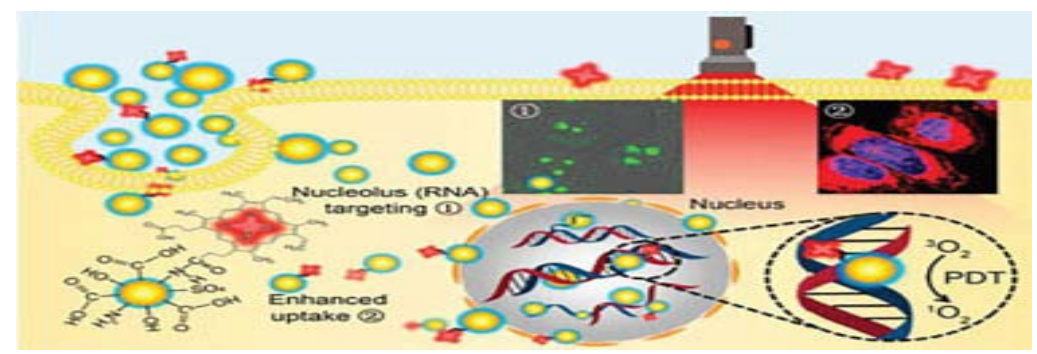

Fig. 6: Graphical representation showing the preparation carbon dots, and its improved nucleus-targeted photodynamic therapy application, [Reproduced with permission (DeRosa, 2002), Copyright 2018, American Chemical Society]

Table 13: Role of CDs in photo-dynamic therapy (PDT) and photo-thermal (PTT) therapy

\begin{tabular}{|c|c|c|c|c|}
\hline S. No. & Source molecule & Ligand attached & Targeted cell type & Refs. \\
\hline 1. & Dopamine & - & HeLa cells & [419] \\
\hline 2. & Citric acid and urea & - & HeLa & [423] \\
\hline 3. & Urea & - & HeLa cells & [425] \\
\hline 4. & Polythiophene phenyl propionic acid & - & HeLa cells & [421] \\
\hline 5. & Citric acid and 5, 10,15, 20-tetrakis(4-aminophenyl) porphyrin & Cetuximab(C225) & HCC827 and MDA-MB-231 cells & [427] \\
\hline 6. & $m$-Phenylenediamine and L-Cysteine & Protoporphyrnix & HeLa & [420] \\
\hline 7. & Diaminohexane and carboxylic group of $\mathrm{Ce} 6$ & Ce6-HA (hyaluronate) & B16F10 melanoma & [426] \\
\hline 8. & EDTA-2Na and $\mathrm{CuCl}_{2}$ & - & Murine melanoma (B 16) cells & [424] \\
\hline 9. & Acrylic acid, 1,2-ethylenediamine (EDA) and $\mathrm{Mg}(\mathrm{OH})_{2}$ & $\mathrm{Mg} / \mathrm{N}$ & HePG2 & [418] \\
\hline 10. & Hydrophobic cyanin dye and poly (ethylene glycol) & - & HePG2, CT26 & [422] \\
\hline
\end{tabular}

\section{CONCLUSION}

In this article, recent developments in the field of CDs, concentrating on their synthetic approaches, surface modification methods, various optical properties and their applications in bioimaging, photocatalysis, biosensing and drug delivery and anti-fungal effects and antiviral effects have been discussed. Furthermore, the superior recognition capabilities of CDs in biosensors and theranostic applications also make them the favourable choice for the development of new diagnostic and treatment devices in many biomedical and environmental applications as well as the early determination of different kinds of sicknesses and environmental contaminations. In the inquisition for novel alternative antimicrobial approaches that are not only effective in mitigating the threat of resistant microorganisms but also benign and nontoxic, CDs have emerged to represent a promising new platform for visible/natural light-activated microbicidal agents. The excellent potential of the CDs platform in the killing/inhibition of bacteria, fungi, and viruses, including some multi-drug resistant species, has been demonstrated in many reported studies, so has been the path towards theragnostic uses, as highlighted in this review article.

\section{ACKNOWLEDGEMENT}

Authors would like to acknowledge the Scientific Writing Cell, Gitam University, Hyderabad and Guru Nanak Institutions Technical Campus, Hyderabad for the support provided towards language editing of the manuscript.

\section{FUNDING}

Nil

\section{AUTHORS CONTRIBUTIONS}

All the author have contributed equally.

\section{CONFLICTS OF INTERESTS}

There are no conflicts of interest

\section{REFERENCES}

1. Mishra V, Patil A, Thakur S, Kesharwani P. Carbon dots: emerging theranostic nanoarchitectures. Drug Discovery Today 2018;23:1219-32.

2. Xiao C, Lai L, Zhang L. Spectroscopic and isothermal titration calorimetry studies of binding interactions between carbon nanodots and serum albumins. J Solution Chem 2018;47:143848.

3. Dong Y, Wang R, Li H, Shao J, Chi Y, Lin X, et al. Polyaminefunctionalized carbon quantum dots for chemical sensing. Anal Chem 2012;84:6220-4.

4. Peng H, Zhang L, Kjallman THM, Soeller C. DNA hybridization detection with blue luminescent quantum dots and dye-labeled single-stranded DNA. Communication 2007;129:3048-9.

5. Zhang Y, Cui P, Zhang F, Feng X, Wang Y, Yang Y, et al. Fluorescent probes for "off-on" highly sensitive detection of Hg2+and l-cysteine based on nitrogen-doped carbon dots. Talanta 2016;152:288-300.

6. Gao X, Cui Y, Levenson RM, Chung LW, Nie S. In vivo cancer targeting and imaging with semiconductor quantum dots. Nat Biotechnol 2004;22:969-76.

7. Liu C, Zhang P, Zhai X, Tian F, Li W, Yang J, et al. Nanocarrier for gene delivery and bioimaging based on carbon dots with PEI passivation enhanced fluorescence. Biomaterials 2012;33:3604-13.

8. Sharma S, Singh N, Nepovimova E. Interaction of synthesized nitrogen enriched graphene quantum dots with novel antiAlzheimer's drugs: spectroscopic insights. J Biomol Struct Dyn 2020;38:1822-37.

9. Tao H, Yang K, Ma Z, Wan J, Zhang Y, Kang Z, et al. In vivo NIR fluorescence imaging, biodistribution, and toxicology of photoluminescent carbon dots produced from carbon nanotubes and graphite. Small 2012;8:281-90.

10. Sharma V, Tiwari P, Mobin SM. Sustainable carbon-dots: recent advances in green carbon dots for sensing and bioimaging. J Mater Chem B 2017;5:8904-24. 
11. Chen F, Gao W, Qiu X, Zhang H, Liu L, Liao P, et al. Graphene quantum dots in biomedical applications: recent advances and future challenges. Front Lab Med 2017;1:192-9.

12. Boakye Yiadom KO, Kesse S, Opoku Damoah Y. Carbon dots: applications in bioimaging and theranostics. Int J Pharm 2019;564:308-17.

13. S Zhu. The photoluminescence mechanism in carbon dots (graphene quantum dots, carbon nanodots, and polymer dots): current state and future perspective. Nano Res 2015;8:355-81.

14. M Bacon, SJ Bradley, T Nann. Graphene quantum dots, Part. Part Syst Charact 2014;31:415-28.

15. S Zhu. Strongly green-photoluminescent graphene quantum dots for bioimaging applications. Chem Commun 2011;47:6858-60.

16. Tao S, Zhu S, Feng T, Xia C, Song Y, Bai Y. The polymeric characteristics and photoluminescence mechanism in polymer carbon dots: a review. Mater Today Chem 2017;6:13-25.

17. Sun X, Lei Y. Fluorescent carbon dots and their sensing applications. Trends Anal Chem 2017;89:163-80.

18. Shamsipur M, Barati A, Karami S. Long-wavelength, multicolor, and white-light-emitting carbon-based dots: achievements made, challenges remaining, and applications. Carbon 2017;124:429-72.

19. Arora N, Sharma NN. Arc discharge synthesis of carbon nanotubes: comprehensive review. Diamond Relat Mater 2014;50:135-50.

20. Schmidt Mende L, Bach U, Humphry Baker R, Horiuchi T, Miura $\mathrm{H}$, Ito $\mathrm{S}$, et al. Organic dye for highly efficient solid-state dyesensitized solar cells. Adv Mater 2005;17:813-5.

21. Shimizu KT, Neuhauser RG, Leatherdale CA, Empedocles SA, Woo W, Bawendi MG. Blinking statistics in single semiconductor nanocrystal quantum dots. Phys Rev B 2001;63:205316.

22. Han M, Gao X, Su JZ, Nie S. Quantum-dot-tagged microbeads for multiplexed optical coding of biomolecules. Nat Biotechnol 2001;19:63.

23. Medintz IL, Uyeda HT, Goldman ER, Mattoussi H. Quantum dot bioconjugates for imaging, labelling and sensing. Nat Mater 2005; 4:435.

24. PG Luo. Carbon-based quantum dots for fluorescence imaging of cells and tissues. RSC Adv 2014;4:10791-807.

25. Guo Y, Wang Z, Shao H, Jiang X. Hydrothermal synthesis of highly fluorescent carbon nanoparticles from sodium citrate and their use for the detection of mercury ions. Carbon 2013;52:583-9.

26. F Yuan. Shining carbon dots: synthesis and biomedical and optoelectronic applications. Nano Today 2016;11:565-86.

27. Pan D, Guo L, Zhang J, Xi C, Xue Q, Huang H, et al. Cutting sp2 clusters in graphene sheets into colloidal graphene quantum dots with strong green fluorescence. J Mater Chem 2012;22:3314-8.

28. Jie G, Huang H, Sun X, Zhu JJ. Electrochemiluminescence of CdSe quantum dots. for immune sensing of human prealbumin. Biosens Bioelectron 2008;23:1896-9.

29. Liu X, Jiang H, Lei J, Ju H. Anodic electrochemiluminescence of CdTe quantum dots and its energy transfer for detection of catechol derivatives. Anal Chem 2007;79:8055-60.

30. GAM Hutton, BCM Martindale, E Reisner. Carbon dots as photosensitisers for solar-driven catalysis. Chem Soc Rev 2017;46:6111-23.

31. J Wang, J Qiu. A review of carbon dots in biological applications. J Materials Sci 2016;51:4728-38.

32. SY Lim, W Shen, Z Gao. Carbon quantum dots and their applications. Chem Soc Rev 2015;44:362-81.

33. Lin H, Ding L, Zhang B, Huang J. Detection of nitrite based on fluorescent carbon dots by the hydrothermal method with folic acid. R Soc Open Sci 2018;5:2054-5703.

34. Shan X, Chai L, Ma J, Qian Z, Chen J, Feng H. B-doped carbon quantum dots as a sensitive fluorescence probe for hydrogen peroxide and glucose detection. Analyst 2014;139:2322-5

35. Guo X, Zhu Y, Zhou L, Zhang L, You Y, Zhang H, Hao J. A simple and green approach to prepare carbon dots with $\mathrm{pH}$-dependent fluorescence for patterning and bioimaging. RSC Adv 2018;8:38091-9.

36. Wu X, Tian F, Wang W, Chen J, Wu M, Zhao JX. Fabrication of highly fluorescent graphene quantum dots using l-glutamic acid for in vitro/in vivo imaging and sensing. J Mater Chem $\mathrm{C}$ 2013;1:4676-84.

37. XT Zheng. Glowing graphene quantum dots and carbon dots: properties, syntheses, and biological applications. Small 2015;11:1620-36.

38. Xu X, Ray R, Gu Y, Ploehn HJ, Gearheart L, Raker K, et al. Electrophoretic analysis and purification of fluorescent singlewalled carbon nanotube fragments. J Am Chem Soc 2004;126:12736-7.

39. Sun YP, Zhou B, Lin Y, Wang W, Fernando KA, Meziani MJ, et al. Quantum-sized carbon dots for bright and colorful photoluminescence. J Am Chem Soc 2006;128:7756-7.

40. Li H, Kang Z, Liu Y, Lee ST. Carbon nanodots: synthesis, properties and applications. J Mater Chem 2012;22:24230-53.

41. Zuo J, Jiang T, Zhao X, Xiong, S, Zhu Z. Preparation and application of fluorescent carbon dots. J Nanomaterials 2015 https://doi.org/10.1155/2015/787862

42. Zhou J, Booker C, Li R, Zhou X, Sham T, Sun X, et al. An electrochemical avenue to blue luminescent nanocrystals from multiwalled carbon nanotubes (MWCNTs). J Am Chem Soc 2007;129:744-5.

43. Zheng L, Chi Y, Dong Y, Lin J, Wang B. Electrochemiluminescence of water-soluble carbon nanocrystals released electrochemically from graphite. J Am Chem Soc 2009;131:4564-5.

44. Li H, He X, Kang Z. Water-soluble fluorescent carbon quantum dots and photocatalyst design. Angewandte Chem 2010;49:4430-4.

45. Ray S, Saha A, Jana NR. Fluorescent carbon nanoparticles: synthesis, characterization, and bioimaging application. J Phys Chem C 2009;113:18546-51.

46. J Zhou, C Booker, R Li, X Zhou, TK Sham, X Sun Z. Ding. J Am Chem Soc 2007;129:744.

47. DB Shinde, VK Pillai. Electrochemical preparation of luminescent graphene quantum dots from multiwalled carbon nanotubes. Chem Eur J 2012;18:12522.

48. Bao L, Zhang L, Tian ZQ Zhang L, Liu C, Lin Y, et al. Electrochemical tuning of luminescent carbon nanodots: from preparation to luminescence mechanism. Adv Mater 2011;23:5801.

49. Zheng L, Chi Y, Dong Y, Lin J, Wang B. Electrochemiluminescence of water-soluble carbon nanocrystals released electrochemically from graphite. J Am Chem Soc 2009;131:4564.

50. QL Zhao, ZL Zhang, BH Huang, J Peng, M Zhang, DW Pang. Facile preparation of low cytotoxicity fluorescent carbon nanocrystals by electrooxidation of graphite. Chem Commun 2008;41:5116-8.

51. Nakamura M, Canevari TC, Cincotto FH. High performance electrochemical sensors for dopamine and epinephrine using nanocrystalline carbon quantum dots obtained under controlled chronoamperometric conditions. Electrochim Acta 2016;209:464-70.

52. Peng H, Travas Sejdic J. Simple aqueous solution route to luminescent carbogenic dots from carbohydrates. Chem Mater 2009;21:5563-5.

53. Xiao J, Liu P, Wang CX, Yang GW. External field-assisted laser ablation in liquid: an efficient strategy for nanocrystal synthesis and nanostructure assembly. Diamond Relat Mater 2017;87:140-220.

54. YP Sun, B Zhou, Y Lin. Quantum-sized carbon dots for bright and colorful photoluminescence. J Am Chem Soc 2006;128:7756-7.

55. V Thongpool, P Asanithi, P Limsuwan. Synthesis of carbon particles using laser ablation in ethanol. Procedia Eng 2012;32:1054-60.

56. C Donate Buendia, R Torres Mendieta, A Pyatenko, E Falomir, M Fernandez Alonso, G Minguez Vega. Fabrication by laser irradiation in a continuous flow jet of carbon quantum dots for fluorescence imaging. ACS Omega 2018;3:2735-42.

57. Li H, Kang Z, Liu Y. Carbon nanodots: synthesis, properties and applications. J Mater Chem 2012;22:24230-53.

58. Wang D, Wang Z, Zhan Q. Facile and scalable preparation of fluorescent carbon dots for multifunctional applications. Engineering 2017;3:402-8.

59. Wang $Q$, Huang $X$, Long Y. Hollow luminescent carbon dots for drug delivery. Carbon 2013;59:192-9.

60. Lu L, Zhu Y, Shi C, Pei YT. Large-scale synthesis of defectselective graphene quantum dots by ultrasonic-assisted liquidphase exfoliation. Carbon 2016;109:373-83. 
61. Xu X, Ray R, Gu Y. Electrophoretic analysis and purification of fluorescent single-walled carbon nanotube fragments. J Am Chem Soc 2004;126:12736-7.

62. M Bottini, C Balasubramanian, MI Dawson, A Bergamaschi, S Bellucci, T Mustelin. Isolation and characterization of fluorescent nanoparticles from pristine and oxidized electric arc-produced single-walled carbon nanotubes. J Phys Chem B 2006;110:831-6.

63. S Dey, A Govindaraj, K Biswas, CNR Rao. Luminescence properties of boron and nitrogen doped graphene quantum dots prepared from arc-discharge-generated doped graphene samples. Chem Phys Lett 2014;595:203-8.

64. Yang S, Sun J, Li X, Zhou W, Wang, He P, et al. Largescale fabrication of heavy doped carbon quantum dots with tunable photoluminescence and sensitive fluorescence detection. J Mater Chem A 2014;8660-7.

65. Hu SL, Niu KY, Sun J, Yang J, Zhao NQ, Du XW. One step synthesis of fluorescent carbon nanoparticles by laser irradiation. J Mater Chem 2009;19:484-8.

66. Tuerhong M, Yang X, Xue-Bo Y. Review on carbon dots and their applications. Chin J Anal Chem 2017;45:139-50.

67. Zeng YW, Ma DK, Wang W, Chen JJ, Zhou L, Zheng YZ, et al. N, S co-doped carbon dots with orange luminescence synthesized through polymerization and carbonization reaction of amino acids. Appl Surf Sci 2015;342:136-43.

68. Zhu S, Meng Q, Wang L, Zhang J, Song Y, Jin H, et al. Highly photoluminescent carbon dots for multicolor patterning sensors, and bioimaging. Angrew Chem Int Ed 2013;52:1-6.

69. Bhunia SK, Saha A, Maity A. R, Ray SC, Jana NR. Carbon nanoparticle-based fluorescent bioimaging probes. Sci Rep 2013;3:1-7.

70. Xu Y, Wu M, Liu Y, Feng XZ, Yin XB, He XW, et al. Nitrogendoped carbon dots: a facile and general preparation method, photoluminescence investigation, and imaging applications. Chem Eur J 2013;19:2276-83.

71. Bourlinos AB, Stassinopoulos A, Anglos D, Zboril R, Georgakilas V, Giannelis EP. Photoluminescent carbogenic dots. Chem Mater 2008;20:4539-41.

72. BCM Martindale, GAM Hutton, CA Caputo, E Reisner. Solar hydrogen production using carbon quantum dots and a molecular nickel catalyst. J Am Chem Soc 2015;137:6018-25.

73. Guo Y, Zhang L, Cao F, Leng Y. Thermal treatment of hair for the synthesis of sustainable carbon quantum dots and the applications for sensing $\mathrm{Hg}^{2+}$. Sci Rep 2016;6:35795.

74. Rong M, Feng Y, Wang Y, Chen X. One-pot solid phase pyrolysis synthesis of nitrogen-doped carbon dots for Fe3+sensing and bioimaging. Sensors Actuators B: Chem 2017;245:868-74.

75. Zhu H, Wang X, Li Y, Wang Z, Yang F, Yang X. Microwave synthesis of fluorescent carbon nanoparticles with electrochemiluminescence properties. Chem Commun 2009;34:5118-20.

76. Wei X, Xu Y, Li Y, Yin X, He X. Ultrafast synthesis of nitrogendoped carbon dots via neutralization heat for bioimaging and sensing. RSC Adv 2014;4:44504-8.

77. Zeng YW, Ma DK, Wang W, Chen JJ, Zhou L, Zheng YZ, et al. N, S co-doped carbon dots with orange luminescence synthesized through polymerization and carbonization reaction of amino acids. Appl Surf Sci 2015;342:136-43.

78. Zhai $\mathrm{X}$, Zhang $\mathrm{P}$, Liu C, Bai $\mathrm{T}$, Li W, Da L, et al. Highly luminescent carbon nanodots by microwave-assisted pyrolysis. Chem Commun 2012;48:7955-7.

79. Liu Y, Xiao N, Gong N, Wang H, Shi X, Gu W, et al. Microwaveassisted polyol synthesis of gadolinium-doped green luminescent carbon dots as a bimodal nanoprobe. Carbon 2014;30:10933-9.

80. Zhu H, Wang X, Li Y, Wang Z, Yang F, Yang X. Microwave synthesis of fluorescent carbon nanoparticles with electrochemiluminescence properties. Chem Commun. 2009;34:5118-20.

81. Kiran S, Misra RDK. Mechanism of intracellular detection of glucose through nonenzymatic and boronic acid functionalized carbon dots. J Biomed Mater Res Part A 2015;103:2888-97.

82. L Cao, S Sahu, P Anilkumar, CE Bunker, J Xu, KAS Fernando, et al. J Am Chem Soc 2011;133:4754.

83. Liu C, Chang K, Guo W, Li H, Shen L, Chen W, et al. Negative differential resistance and multilevel resistive switching in $\mathrm{BaSrTiO}_{3}$ films. Appl Phys Lett 2014;105:073306.
84. Wang F, Xie Z, Zhang H, Liu CY, Zhang YG. Highly luminescent organosilane-functionalized carbon dots. Adv Funct Mater 2011;21:1027-31.

85. Wan JY, Yang Z, Liu ZG, Wang HX. Ionic liquid-assisted thermal decomposition synthesis of carbon dots and graphene-like carbon sheets for optoelectronic application. RSC Adv 2016;6:61292-300.

86. Q Wang. Hollow luminescent carbon dots for drug delivery. Carbon 2013;59:192-9.

87. Wang W, Lu Y, Huang H, Feng J, Chen J, Wang A. Facile synthesis of water-soluble and biocompatible fluorescent nitrogen-doped carbon dots for cell imaging. Analyst 2014;139:1692-6.

88. M Thakur, Sunil Pandey, Ashmi Mewada, Vaibhav Patil, Monika Khade, Ekta Goshi. Antibiotic conjugated fluorescent carbon dots as a theranostic agent for controlled drug release, bioimaging, and enhanced antimicrobial activity. J Drug Delivery 2014;1-9. DOI:10.1155/2014/282193

89. Cao X, Wang Q, Zhou J, Deng W, Yu Q Chen J, et al. Porphyra polysaccharide-derived carbon dots for nonviral co-delivery of different gene combinations and neuronal differentiation of ectodermal mesenchymal stem cells. Nanoscale 2017;9:10820-31.

90. Yang W, Nie H, Gong Y, Jing J, Gao L. Turn-on theranostic fluorescent nanoprobe by electrostatic self-assembly of carbon dots with doxorubicin for targeted cancer cell imaging, in vivo hyaluronidase analysis, and targeted drug delivery. Biosens Bioelectron 2017;96:300-7.

91. YF Wu. Multi-functionalized carbon dots as theranostic nanoagent for gene delivery in lung cancer therapy. Sci Rep 2016;6:21170.

92. Ding H, Du F, Liu P, Chen Z, Shen J. DNA-carbon dots function as fluorescent vehicles for drug delivery. ACS Appl Mater Interfaces 2015;7:6889-97.

93. Reckmeier CJ, Schneider J, Xiong Y, Hausler J, Kasak P, Schnick W, et al. Aggregated molecular fluorophores in the ammonothermal synthesis of carbon dots. Chem Mater 2017;29:10352-61.

94. Ding H, Ji Y, Wei JS, Gao QY, Zhou ZY, Xiong HM. Facile synthesis of red-emitting carbon dots from pulp-free lemon juice for bioimaging. J Mater Chem B 2017;5:5272-7.

95. Zhang Z, Pei K, Yang Q, Dong J, Yan Z, Chen J. A nanosensor made of sulfur-nitrogen co-doped carbon dots for "off-on" sensing of hypochlorous acid and $\mathrm{Zn}$ (II) and its bioimaging properties. New J Chem 2018;42:15895-904.

96. J Ge. Red-emissive carbon dots for fluorescent, photoacoustic, and thermal theranostics in living mice. Adv Mater 2015;27:4169-77.

97. Sun X, Lei Y. Fluorescent carbon dots and their sensing applications. Trends Anal Chem 2017;89:163-80.

98. Xue M, Zhang L, Zhan Z, Zou M, Huang Y, Zhao S. Sulfur and nitrogen binary doped carbon dots derived from ammonium thiocyanate for selective probing doxycycline in living cells and multicolor cell imaging. Talanta 2016;150:324-30.

99. Wang Y, Gao D, Chen Y, Hu G, Liu H, Jiang Y. Development of $\mathrm{N}, \mathrm{S}$-doped carbon dots as a novel matrix for the analysis of small molecules by negative ion MALDI-TOF MS. RSC Adv 2016;6:79043-9.

100. Yang Z, Li Z, Xu M, Ma Y, Zhang J, Su Y, et al. Controllable synthesis of fluorescent carbon dots and their detection application as nanoprobes. Nano-Micro Lett 2013;5:247-59.

101. Wu F, Su H, Cai Y, Wong WK, Jiang W, Zhu X. Porphyrinimplanted carbon nanodots for photoacoustic imaging and in vivo breast cancer ablation. ACS Appl Biol Mater 2018;1:110-7.

102. Hu S, Wei Z, Chang Q, Trinchi A, Yang J. A facile and green method towards coal Base fluorescent carbon dots with photocatalytic activity. Appl Surf Sci 2016;378:402-7.

103. Amin N, Afkhami A, Madrakian T. Construction of a novel "offon" fluorescence sensor for highly selective sensing of selenite based on europium ions induced crosslinking of nitrogendoped carbon dots. JOL 2018;194:768-77.

104. Atashi M, Naghdi T, Golmohammadi H, Saeedi I, Alanezhad M. Carbon quantum dots originated from chitin nanofibers as a fluorescent chemoprobe for drug sensing. J Ind Eng Chem 2017;52:162-7.

105. Shen P, Xia Y. Synthesis-modification integration: one-step fabrication of boronic acid functionalized carbon dots for fluorescent blood sugar sensing. Anal Chem 2014;86:5323-9. 
106. Li C, Liu W, Sun X, Pan W, Wang J. Multi sensing functions integrated into one carbon dot-based platform via different types of mechanisms. Sens Actuators B 2017;252:544-53.

107. Thakur M, Pandey S, Mewada A. Antibiotic conjugated fluorescent carbon dots as a theranostic agent for controlled drug release, bioimaging, and enhanced antimicro-bial activity. J Drug Delivery 2014;2014:282193.

108. Norrby SR, Nord CE, Finch R, In ESCM. Lack of development of new antimicrobial drugs: a potential serious threat to public health. Lancet Infect Dis 2005;5:115-9.

109. J Song, J Li, Z Guo. A novel fluorescent sensor based on sulfur and nitrogen co-doped carbon dots with excellent stability for selective detection of doxycycline in raw milk. RSC Adv 2017;7:12827-34.

110. Zhao C, Jiao Y, Zhang L, Yang Y. One-step synthesis of S, B codoped carbon dots and their application for selective and sensitive fluorescence detection of diethyl-stilbestrol. New J Chem 2018;4:2857-64.

111. Harroun SG, Chen SY, Unnikrishnan B, Li YJ, Huang CC. Solidstate synthesis of self functional carbon quantum dots for detection of bacteria and tumor cells. Sensors Actuators B Chem 2016;228:465-70.

112. Zhong D, Zhuo Y, Feng Y, Yang X. Employing carbon dots modified with vancomycin for assaying gram-positive bacteria like staphylococcus aureus. Biosensors Bioelectro-nics 2015;74:546-53.

113. Xu H, Yang X, Li G, Zhao C, X Liao X. Green synthesis of fluorescent carbon dots for selective detection of tartrazine in food samples. J Agric Food Chem 2015;63:6707-14.

114. Hu J, Bao Z, Tang W, Wu H, Pan J, Xu X, et al. Surface state engineering carbon dots as multi-band active sensitizers for $\mathrm{ZnO}$ nanowire array photoanode to boost solar water splitting. Carbon 2017;121:201-8.

115. Yang J, Zhang X, Ma YH, Gao G, Chen X, Jia HR, et al. Carbon dotbased platform for simultaneous bacterial distinguishment and antibacterial applications. Acs Appl Mater Inter 2016;8:32170-81.

116. Yang J. One-step synthesis of carbon dots with bacterial contact-enhanced fluorescence emission: fast gram-type identification and selective gram-positive bacterial inactivation. Carbon 2019;146:827-39.

117. Dong XL, Al Awak M, Tomlinson N, Tang YG, Sun YP, Yang LJ. Antibacterial effects of carbon dots in combination with other antimicrobial reagents. Plos One 2017;12:0185324.

118. Huang SM, Gu JJ, Ye J, Fang B, Wan SF, Wang CY, et al. Benzoxazine monomer derived carbon dots as a broadspectrum agent to block viral infectivity. J Colloid Interf Sci 2019;542:198-206.

119. Sun S, Chen J, Jiang K, Tang Z, Wang Y, Li Z, et al. Ce6-modified carbon dots for multimodal-imaging-guided and single-nirlaser-triggered photothermal/photodynamic synergistic cancer therapy by reduced irradiation power. ACS Appl Mater Interfaces 2019;11:5791-803.

120. Geng B, Yang D, Pan D, Wang L, Zheng F, Shen W, et al. NIRresponsive carbon dots for efficient photothermal cancer therapy at low power densities. Carbon 2018;134:153-62.

121. Yang J, Zhang X, Ma YH, Gao G, Chen X, Jia HR, et al. Carbon dotbased platform for simultaneous bacterial distinguishment and antibacterial applications. ACS Appl Mater Interfaces 2016;8:32170-81.

122. Wang M, Hou C, Chen S. Facile preparation of carbon-dotsupported nanoflowers for efficient photothermal therapy of cancer cells. Dalton Trans 2018;47:1777-81.

123. Cao L, Wang X, Meziani MJ. Carbon dots for multiphoton bioimaging. J Am Chem Soc 2007;129:11318-9.

124. Qu D, Zheng M, Du P, Zhou Y, Zhang L, Li D, et al. Highly luminescent $\mathrm{S}, \mathrm{N}$ co-doped graphene quantum dots with broad visible absorption bands for visible light photocatalysts. Nanoscale 2013;5:12272-7.

125. Da Silva JCE, Gonc,alves HM. Analytical and bioanalytical applications of carbon dots. TrAC Trends Anal Chem 2011;30:1327-36.

126. Xu XY, Ray R, Gu YL, Ploehn HJ, Gearheart L, Raker K. Electrophoretic analysis and purification of fluorescent singlewalled carbon nanotube fragments.J Am Chem Soc 2004;126:12736-7.
127. Dang H, Huang LK, Zhang Y, Wang CF, Chen S. Large-scale ultrasonic fabrication of white fluorescent carbon dots. Ind Eng Chem Res 2016;55:5335-41.

128. Ray S, Saha A, Jana NR, Sarkar R. Fluorescent carbon nanoparticles: synthesis, characterization, and bioimaging application. J Phys Chem C 2009;113:18546-51.

129. Peng H, Sejdic JT. Simple aqueous solution route to luminescent carbogenic dots from carbohydrates. Chem Mater 2009;21:5563-5.

130. Sun X, Lei Y. Fluorescent carbon dots and their sensing applications. TrAC Trend Anal Chem 2017;89:163-80.

131. Anwar S, Ding H, Xu M, Hu X, Li Z, Wang J. Recent advances in synthesis, optical properties, and biomedical applications of carbon dots. ACS Appl Bio Mater 2019;2:2317-38.

132. P Mirtchev. Solution phase synthesis of carbon quantum dots as sensitizers for nanocrystalline TiO2 solar cells. J Mater Chem 2012;22:1265-9.

133. Deng J, Lu Q, Mi N, Li H, Liu M, Xu M, et al. Electro-chemical synthesis of carbon nanodots directly from alcohols. Chem A Eur J 2014;20:4993-9.

134. H Ming, Z Ma, Y Liu, K Pan, H Yu, F Wang, et al. Large scale electrochemical synthesis of high-quality carbon nanodots and their photocatalytic property. Dalton Trans 2012;41:9526-31.

135. Song Y, Shi W, Chen W, Li X, Ma H. Fluorescent carbon nanodots conjugated with folic acid for distinguishing folate-receptorpositive cancer cells from normal cells. J Mater Chem 2012;22:12568-73.

136. Wang Y, Hu A. Carbon quantum dots: synthesis, properties and applications. J Materials Chem C 2014;2:1621-39.

137. Lu S, Sui L, Liu J, Zhu S, Chen A, Jin M, et al. Nearinfrared photoluminescent polymer-carbon nanodots with twophoton fluorescence. Adv Mater 2017;29:1603443.

138. Zhu H, Wang X, Li Y, Wang Z, Yang F, Yang X. Microwave synthesis of fluorescent carbon nanoparticles with electrochemiluminescence properties. Chem Commun 2009;34:1518-20.

139. Ji R, Cao X, Lin J, Jiang H, Li X, Teng KS, et al. Deep ultraviolet photoluminescence of water-soluble self-passivated graphene quantum dots. ACS Nano 2012;6:5102-10.

140. Kuruvilla SJ, Li S, Sansalone L, Fortes B, Zheng I, Blackwelder P, et al. Dihydrolipoic acid conjugated carbon dots accelerate human insulin fbrillation. J Parkinsons Dis Alzheimer Dis 2015;2:1-7.

141. Zhang Y, Cui P, Zhang F, Feng X, Wang Y, Yang Y, et al. Fluorescent probes for "of-on" highly sensitive detection of $\mathrm{Hg} 2+$ and l-cysteine based on nitrogen-doped carbon dots. Talanta 2016;152:288-300.

142. P Mirtchev. Solution phase synthesis of carbon quantum dots as sensitizers for nanocrystalline TiO2 solar cells. J Mater Chem 2012;22:1265-9.

143. L Ji R, Cao X, Lin J, Jiang H, Li X, Teng KS, et al. Deep ultraviolet photoluminescence of water-soluble self-passivated graphene quantum dots. ACS Nano 2012;6:5102-10.

144. Liu H, Wang Q, Shen G, Zhang C, Li C, Ji W, et al. A multifunctional ribonuclease a-conjugated carbon dot nanosystem cluster for synchronous cancer imaging and therapy. Nanoscale Res Lett 2014;9:397.

145. Zheng M, Xie Z, Qu D, Li D, Du P, Jing X, et al. On-off-on fluorescent carbon dot nanosensor for recognition of chromium (VI) and ascorbic acid based on the inner filter effect. ACS Appl Mater Interfaces 2013;5:13242-7.

146. Liu R, Wu D, Liu S, Koynov K, Knoll W, Li Q. An aqueous route to multicolour photoluminescent carbon dots using silica spheres as carriers. Angew Chem Int Ed 2009;48:4598-601.

147. BC Rai, Nitu Kumari, Rohit Raj, AnwarulHoda. Quantum dots for wastewater: a future purifier. Int J Adv Res Eng Technol 2018;9:93-9.

148. Zhu H, Wang X, Li Y, Wang Z, Yang F, Yang X. Microwave synthesis of fluorescent carbon nanoparticles with electrochemiluminescence properties. Chem Commun 2009;34:1518-20.

149. Zhuo Y, Miao H, Zhong D, Zhu S, Yang X. One-step synthesis of high quantum-yield and excitation-independent emission carbon dots for cell imaging. Mater Lett 2015;139:197-200.

150. $\mathrm{Ru} \mathrm{W,} \mathrm{L} \mathrm{KQ,} \mathrm{Tang} \mathrm{ZR.} \mathrm{Xu} \mathrm{YJ.} \mathrm{Recent} \mathrm{progress} \mathrm{on} \mathrm{carbon}$ quantum dots: synthesis, properties, and applications in photocatalysis. J Mater Chem A 2017;5:3717-3734. 
151. D Pan. Hydrothermal route for cutting graphene sheets into blue-luminescent graphene quantum dots. Adv Mater 2010;22:734-8.

152. Deng J, Lu Q, Mi N, Li H, Liu M, Xu M, et al. Electro-chemical synthesis of carbon nanodots directly from alcohols. Chem A Eur J 2014;20:4993-9.

153. Jiang $Y$, Han $Q$ Jin C, Wang B. A fluorescence turn-of chemosensor based on $\mathrm{N}$ doped carbon quantum dots for detection of Fe3+in aqueous solution. Mater Lett 2015;141:366-8.

154. Lim SY, Shen W, Gao Z. Carbon quantum dots and their applications. Res Gate 2014;44:362-81.

155. Cai QY, Li J, Ge J, Zhang L, Hu YL, Li ZH, et al. A rapid fuorescence "switch-on" assay for glutathione detection by using carbon dots-MnO2 nanocomposites. Biosens Bioelectron 2015;72:31-6.

156. BC Rai, Nitu Kumari, Rohit Raj, Monalisa. Quantum dot confined CDSE semiconductor. Int J Adv Res Eng Technol 2018;9:100-6.

157. Wang Y, Hu A. Carbon quantum dots: synthesis, properties, and applications. J Mater Chem C 2014;2:6921-39.

158. Liu R, Wu D, Liu S. An aqueous route to multicolor photoluminescent carbon dots using silica spheres as carriers. Angew Chem 2009;121:4668-71.

159. Zou C, Foda MF, Tan X, Shao K, Wu L, Lu Z, et al. Carbondot and quantum-dot-coated dual-emission core-satellite silica nanoparticles for ratiometric intracellular $\mathrm{cu}(2+)$ imaging. Anal Chem 2016;88:7395-403.

160. Zhou J, Sheng Z, Han H, Zou M, Li C. Facile synthesis of fluorescent carbon dots using watermelon peel as a carbon source. Mater Lett 2012;66:222-4.

161. Wei X, Xu Y, Li Y, Yin X, He X. Ultrafast synthesis of nitrogendoped carbon dots via neutralization heat for bioimaging and sensing. RSC Adv 2014;4:44504-8.

162. Li Z, Yu H, Bian T, Zhao Y, Zhou C, Shang L, et al. Highly luminescent nitrogen-doped carbon quantum dots as effective fluorescent probes for mercuric and iodide ions. J Mater Chem C 2015;3:1922-8.

163. Martindale BC, Hutton GA, Caputo CA, Reisner E. Solar hydrogen production using carbon quantum dots and a molecular nickel catalyst. J Am Chem soc 2015;137:6018-25.

164. Wang F, Wang S, Sun Z, Zhu H. Study on the ultrasonic singlestep synthesis and optical properties of nitrogen-doped carbon fuorescent quantum dots. Fullerenes Nanotubes Carbon Nano Struct 2015;23:769-76.

165. Wang F, Xie Z, Zhang H, Liu CY, Zhang YG. Highly luminescent organ silane-functionalized carbon dots. Adv Funct Mater 2011;21:1027-103.

166. Ray S, Saha A, Jana NR. Fluorescent carbon nanoparticles: synthesis, characterization, and bioimaging application. J Phys Chem C 2009;113:18546-51.

167. Wang R, Lu KQ, Tang ZR, Xu YJ. Recent progress in carbon quantum dots: synthesis, properties, and applications in photocatalysis. J Mater Chem A 2017;5:3717-34.

168. Sun D, Ban R, Zhang P, Wu G, Zhang J, Zhu J. Hair fiber as a precursor for synthesizing of sulfur and nitrogen-co-doped carbon dots with tunable lumine-cence properties. Carbon 2013;64:424-34.

169. KP Loh. Graphene oxide as a chemically tunable platform for optical applications. Nat Chem 2010;2:1015-24.

170. Q Mei. Fluorescent graphene oxide logic gates for discrimination of iron $\left(3^{+}\right)$and iron $\left(2^{+}\right)$in living cells by imaging. Chem Commun 2012;48:7468-70.

171. Zhuo SM Shao, Lee ST. Up conversion and down conversion fluorescent graphene quantum dots: ultrasonic preparation and photocatalysis. ACS Nano 2012;6:1059-64.

172. Tao H, Yang K, Ma Z, Wan J, Zhang Y, Kang Z, et al. In vivo NIR fluorescence carbo dot produced from carbon nanotubes and graphite. Small 2012;8:281-90.

173. Benito Alifonso D, Tremel S, Hou B, Lockyear H, Mantell L, Fermin DJ, et al. Lactose as a trojan horse for quantum dot cell transport. Angewandte Chem 2014;126:829-33.

174. Gemmill KB, Muttenthaler M, Delehanty JB, Stewart MH, Susumu K, Dawson PE. Evaluation of diverse peptidyl motifs for cellular delivery of semiconductor quantum dots. Anal Bioanal Chem 2013;405:6145-54.
175. Marradi M, Martin Lomas M, Penades MS. Glyconanoparticles polyvalent tools to study carbohydrate-based interactions. Adv Carbohydr Chem Biochem 2010;64:211.

176. Jia X, Pei M, Zhao X, Tian K, Zhou T, Liu P. PEGylated oxidized DOX prodrug conjugate nanoparticles cross-linked with fluorescent carbon dots for tumour theranostics. ACS Biomater Sci Eng 2016;2:1641-8.

177. Cai X, Li X, Liu Y, Wu G, Zhao Y, Chen F, et al. Galactose decorated acid labile nanoparticles encapsulating quantum dots for enhanced cellular uptake and subcellular localization. Pharm Res 2012;29:2167-79.

178. Blanco-Canosa JB, Bradburne CE, Susumu K, Stewart $\mathrm{MH}$, Prasuhn DE, Dawson PE, et al. Site-specific cellular delivery of quantum dots with chemoselectively-assembled modular peptides. Chem Commun 2013;49:7878-80.

179. Boeneman K, Delehanty JB, Blanco Canosa JB, Susumu K, Stewart $\mathrm{MH}$, Husston $\mathrm{AL}$, et al. Walters, selecting improved peptidyl motifs for cytosolic delivery of disparate protein and nanoparticle materials. Acs Nano 2013;7:3778-96.

180. Xu P, Li J, Shi L, Selke MB, Chen X, Wang. Synergetic effect of functional cadmium-tellurium quantum dots conjugated with gambogic acid for HepG2 cell-labeling and proliferation inhibition. Int J Nanomed 2013;8:3729.

181. Liu BR, YW Huang JG, Winiarz HJ, Chiang HJ, Lee. Intracellular delivery of quantum dots mediated by a histidine-and argininerich HR9 cell penetrating peptide through the direct membrane translocation mechanism. Biomaterials 2011;32:3520-37.

182. Tan T, Wan A, Li H. $\mathrm{Ag}_{2} \mathrm{~S}$ quantum dots conjugated chitosan nanospheres toward light-triggered nitric oxide release and near-infrared fluorescence imaging, Langmuir 2013;2:15032-42.

183. Wen CJ, Sung CT, Aljuffali IA, Huang YJ, Fang JY. Nanocomposite liposomes containing quantum dots and anticancer drugs for bioimaging and therapeutic delivery: a comparison of cationic, PEGylated and deformable liposomes. Nanotechnology 2013;24:325101.

184. Wang J, Li Q, Zhou JE, Wang Y, Yu L, Peng H, et al. Synthesis, characterization and cells and tissues imaging of carbon quantum dots. Opt Mater 2017a;72:15-9.

185. Guo XL, Ding ZY, Deng SM, Shen XC, Jiang BP, Liang H. A novel strategy of transition-metal doping to engineer absorption of carbon dots for near-infrared photothermal/photophotothermal/photodynamic therapies. Carbon 2019;19:519-30.

186. Zheng XT, Ananthanarayanan A, Luo KQ, Chen P. Glowing graphene quantum dots and carbon dots: properties, syntheses, and biological applications. Small 2015b;11:1620-36.

187. Wu F, Su H, Cai Y, Wong WK, Jiang W, Zhu X. Porphyrinimplanted carbon nanodots for photoacoustic imaging and in vivo breast cancer ablation. ACS Appl Biol Mater 2018;1:110-7.

188. Campos BB, Oliva MM, Caceres RC, Castellon ER, Jimenez JJ, da Silva JCGE, et al. Carbon dots on based folic acid coated with PAMAM dendrimer as platform for Pt(IV) detection. J Colloid Interface Sci 2016;465:165-73.

189. Gao L, Zhao X, Wang J, Wang Y, Yu L, Peng H, et al. Multiplefunctionalized carbon quantum dots for targeting glioma and tissue imaging. Opt Mater 2018b;75:764-9.

190. Beack S, Kong WH, Jung HS, Do IH, Han S, Kim H, et al. Photodynamic therapy of melanoma skin cancer using carbon dotchlorin e6-Hyaluronate conjugate. Acta Biomater 2015;26:295-305.

191. Zheng DW, Li B, Li CX, Fan JX, Lei Q, Li C, et al. Carbondotdecorated carbon nitride nanoparticles for enhanced photodynamic therapy against hypoxic tumor via water splitting. ACS Nano 2016;10:8715-22.

192. Yao YY, Gedda G, Girma WM, Yen CL, Ling YC, Chang JY Magneto fluorescent carbon dots derived from crab shell for targeted duamodality bioimaging and drug delivery. ACS Appl Mater Interfaces 2017;9:13887-99.

193. Wang Y, Cui Y, Zhao Y, He B, Shi X, Di D, et al. Fluorescent carbon dot-gated multifunctional mesoporous silica nanocarriers for redox/enzyme dual-responsive targeted and controlled drug delivery and real-time bioimaging. Eur J Pharm Biopharm 2018b;117:105-15.

194. Kim D. Graphene quantum dots prevent $\alpha$-synucleinopathy in Parkinson's disease. Nat Nanotechnol 2018;13:812. 
195. Teng X, Ma C, Ge C, Yan M, Yang J, Zhang Y, et al. Green synthesis of nitrogen-doped carbon dots from konjac flour with "Off-On" fluorescence by and L-Lysine for bioimaging. J Mater Chem B 2014;2:4631-9.

196. Sun T, Zheng M, Xie Z, Jing X. Supramolecular hybrids of carbon dots with doxorubicin: synthesis, stability and cellular trafcking. Mater Chem Front 2017;1:354-60.

197. Zhang B, Liu C, Liu Y. A novel one-step approach to synthesize fuorescent carbon nanoparticles. Eur J Inorg Chem 2010;28:4411-4.

198. Malishev R. Chiral modulation of amyloid beta fibrillation and cytotoxicity by enantiomeric carbon dots. Chem Commun 2018;54:7762-5.

199. Zheng M, Liu X, Li J, Qu D, Zhao H, Guan X, et al. Integrating oxaliplatin with highly luminescent carbon dots: an unprecedented theranostic agent for personalized medicine. Adv Mater 2014;21:3554-60.

200. Li H, He X, Liu Y. One-step ultrasonic synthesis of water-soluble carbon nanoparticles with excellent photoluminescent properties. Carbon 2011;49:605-9.

201. Zeng Q, Shao D, He X, Ren Z, Ji W, Shan C, et al. Carbon dots as a trackable drug delivery carrier for localized cancer therapy in vivo. J Mater Chem B 2016;4:5119-26.

202. Hettiarachchi SD, et al. Triple conjugated carbon dots as a nano-drug delivery model for glioblastoma brain tumors. Nanoscale 2019;11:6192-205.

203. Li S, Amat D, Peng Z, Vanni S, Raskin S, Angulo GD, et al. Transferrin conjugated nontoxic carbon dots for doxorubicin delivery to target paediatric brain tumor cells. Nanoscale 2016;8:16662-9.

204. Mewada A, Pandey S, Thakur M, Jadhav D, Sharon M. Swarming carbon dots for folic acid-mediated delivery of doxorubicin and biological imaging. J Mater Chem B 2013;2:698-705.

205. Gao N, Yang W, Nie H, Gong Y, Jing J, Gao L, et al. Turn-on theranostic fluorescent nanoprobe by electrostatic selfassembly of carbon dots with doxorubicin for targeted cancer cell imaging, in vivo hyaluronidase analysis, and targeted drug delivery. Biosens Bio Electron 2017;96:300-7.

206. Wang L, Yin Y, Jain A, Zhou HS. Aqueous-phase synthesis of highly luminescent, nitrogen-doped carbon dots and their application as bioimaging agents. Langmuir 2014;30:14270-5.

207. Qiao ZA, Wang Y, Gao Y, Li H, Dai T, Liu Y, et al. Commercially activated carbon as the source for producing multicolor photoluminescent carbon dots by chemical oxidation. Chem Commun 2010;46:8812-4.

208. Xie Z, Feng Y, Wang F, Chen D, Zhang Q, Zeng Y, et al. Construction of carbon dots modifed MoO3/g-C3N4 Z-scheme photocatalyst with enhanced visible-light photocatalytic activity for the degradation of tetracycline. Appl Catal B 2018;229:96-104.

209. Martindale BC, Hutton GA, Caputo CA, Reisner E. Solar hydrogen production using carbon quantum dots and a molecular nickel catalyst. J Am Chem Soc 2015;137:6018-25.

210. Yang W, Zhang H, Lai J, Peng X, Hu Y, Gu W, et al. Carbon dots with red-shifted photoluminescence by fluorine doping for optical bioimaging. Carbon 2018;128:78-85.

211. Wang F, Wang, Feng Y, Zeng Y, Xie Z. Novel ternary photocatalyst of single atom-dispersed silver and carbon quantum dots co-loaded with ultrathin g-C3N4 for broadspectrum photocatalytic degradation of naproxen. Appl Catal B 2018;221:510-20.

212. Bourlinos AB, Rathi AK, Gawande MB, Hola K, Goswami A. Fe(III)-functionalized carbon dots-highly efcient photoluminescence redox catalyst for hydrogenations of olefns and decomposition of hydrogen peroxide. Appl Mater Today 2017;7:179-84.

213. Parvin N, Mandal TK. Dually emissive $\mathrm{P}, \mathrm{N}$-co-doped carbon dots for fluorescent and photoacoustic tissue-imaging in living mice. Micro Chim Acta 2017;184:1117-2.

214. Photostable, biocompatible nitrogen-doped graphene quantum dots for cellular and deep-tissue imaging. Nano Lett 2013;13:2436-41.

215. Wang J, Gao M, Ho GW. Bidentate-complexes-derived TiO2/carbon dots photocatalysts: in situ synthesis, versatile heterostructures, and enhanced $\mathrm{H} 2$ evolution. J Mater Chem 2014;2:5703-9.

216. Liu C, Zhang P, Zhai X, Tian F, Li W, Yang J, et al. Nanocarrier for gene delivery and bioimaging based on carbon dots with PEI passivation enhanced fuorescence. Biomaterials 2012;33:3604-13.

217. Chen B, Li F, Li S, Weng W, Guo H, Guo T, et al. Large scale synthesis of photoluminescent carbon nanodots and their application for bioimaging. Nanoscale 2013;5:1967-71.

218. Dong Y, Chen C, Zheng X, Gao L, Cui Z, Yang H, et al. One-step and high yield simultaneous preparation of single-and multilayer graphene quantum dots from CX-72 carbon black. J Mater Chem 2012;22:8764-6.

219. Hsu PC, Chang HT. Synthesis of high-quality carbon nanodots from hydrophilic compounds: role of functional groups. Chem Commun 2012;48:3984-6.

220. Que Q, Xing Y, He Z, Yang Y, Yin X. Bi203/Carbon quantum dots hetero structured photocatalysts with enhanced photocatalytic activity. Mater Lett 2017;209:220-3.

221. Sun Y, Wang S, Li C, Luo P, Tao L, Wei Y, et al. Large scale preparation of graphene quantum dots from graphite with tunable fluorescence properties. Phys Chem Chem Phys 2013;15:9907-13.

222. Zhou L, Geng J, Liu B. Graphene quantum dots from polycyclic aromatic hydrocarbon for bioimaging and sensing of Fe3+and hydrogen peroxide. Part Part Syst Charact 2013;30:1086-92.

223. Mehta A, Mishra A, Kainth S, Basu S. Carbon quantum dots/TiO2 nanocomposite for sensing of toxic metals and photodetoxifcation of dyes with kill waste by waste concept. Mater Des 2018;155:485-93.

224. Zhu S, Zhang J, Qiao C, Tang S, Li Y, Yuan W, et al. Strongly green-photoluminescent graphene quantum dots for bioimaging applications. Chem Commun 2011;47:6858-60.

225. Hu C, Liu Y, Yang Y, Cui J, Huang Z, Wang Y, et al. One-step preparation of nitrogen-doped graphene quantum dots from oxidized debris of graphene oxide. J Mater Chem B 2013;1:3942.

226. Krishna AS, Radhakumary C, Sreenivasan K. Detection and imaging of fatty plaques in blood vessels using functionalized carbon dots. Anal Methods 2015;7:9482-8.

227. Wang F, Xie Z, Zhang H, Liu CY, Zhang YG. Highly luminescent organosilane-functionalized carbon dots. Adv Funct Mater 2011;21:1027-31.

228. Joshi PN, Mathias A, Mishra A. Synthesis of eco-friendly fluorescent carbon dots and their biomedical and environmental applications. Mater Technol 2018;33:672-80.

229. Monte SS, Andrade SIE, Lima MB, Araujo MCU. Synthesis of highly fluorescent carbon dots from lemon and onion juices for determination of riboflavin in multivitamin/mineral supplements. J Pharm Anal 2019;9:209-16.

230. Liu W, Diao H, Chang H, Wang H, Li T, Wei W. Green synthesis of carbon dots from rose-heart radish and application for Fe3+detection and cell imaging. Sens Actuators B 2017;241:190-8.

231. Roshni V, Divya O. One-step microwave-assisted green synthesis of luminescent n-doped carbon dots from sesame seeds for selective sensing of $\mathrm{Fe}$ (III). Curr Sci 2017;112:385-90.

232. Li L, Wang X, Fu Z, Cui F. One-step hydrothermal synthesis of nitrogen-and sulfur-co-doped carbon dots from ginkgo leaves and application in biology. Mater Lett 2017;196:300-3.

233. Yao Y, Gedda G, Girma WM, Yen C, Ling Y, Chang J. Magneto fluorescent carbon dots derived from crab shell for targeted dual-modality bioimaging and drug delivery. ACS Appl Mater Interfaces 2017;9:13887-99.

234. Atchudan R, Edison TNJI, Chakradhar D, Perumal S, Shim J, Lee YR. Facile green synthesis of nitrogen-doped carbon dots using chionanthusretusus fruit extract and investigation of their suitability for metal ion sensing and biological applications. Sens Actuators B 2017;246:497-509.

235. Li Z, Zhang Y, Niu Q, Mou M, Wu Y, Liu X, et al. A fluorescence probe based on the nitrogen-doped carbon dots prepared from orange juice for detecting $\mathrm{Hg} 2+$ in water. J Lumin 2017;187:274-80. 
236. Mandani S, Dey D, Sharma B, Sarma TK. Natural occurrence of fluorescent carbon dots in honey. Carbon 2017;119:569-72.

237. Hu Y, Zhang L, Li X, Liu R, Lin L, Zhao S. Green preparation of $s$ and $n$ co-doped carbon dots from water chestnut and onion as well as their tse as atomff fluorescent probe for the quantification and imaging of coenzyme a. ACS Sustainable Chem Eng 2017;5:4992-5000.

238. Aji MP, Wiguna PA. Facile synthesis of luminescent carbon dots from mangosteen peel by pyrolysis method. J Theor Appl Phys 2018;11:119-26.

239. Ng YH, Chin SF, Pang SC, Ng SM. The luminescence profile of carbon dots synthesized from $\alpha$-cellulose under different acid hydrolysis conditions. Opt Mater 2017;70:50-6.

240. Wang J, Qiu F, Li X, Wu H, Xu J, Niu X, et al. A facile one-pot synthesis of fluorescent carbon dots from degrease cotton for the selective determination of chromium ions in water and soil samples. J Lumin 2017;188:230-7.

241. Ding H, Ji Y, Wei J, Gao Q, Zhou Z, Xiong HM. Facile synthesis of red emitting carbon dots from pulp-free lemon juice for bioimaging. J Mater Chem B 2017;5:5272-7.

242. Zheng Y, Zhang H, Li W, Liu Y, Zhang X, Liu H, et al. Pollen derived blue fluorescent carbon dots for bioimaging and monitoring of nitrogen, phosphorus and potassium uptake in brassica parachinensis L. RSC Adv 2017;7:33459-65.

243. Shen J, Shang S, Chen X, Wang D, Cai Y. Facile synthesis of fluorescence carbon dots from sweet potato for Fe3+sensing and cell imaging. Mater Sci Eng C 2017;76:856-64.

244. Yang K, Liu M, Wang Y, Wang S, Miao H, Yang L, et al. Carbon dots derived from fungus for sensing hyaluronic acid and hyaluronidase. Sens Actuators B 2017;251:503-8.

245. Dinc S, Kara M, Kars MD, Ayku IF, Çicekci H, Akkus M. Biocompatible ypgurt carbon dots: evaluation of utilization for medical applications. Appl Phys A: Mater Sci Process 2017;123:572.

246. Zhan Z, Zhao S, Xueb M. Green preparation of fluorescent carbon dots from water chestnut and its application for multi color imaging in living cells. Dig J Nanomater Bios 2017;12:555-64.

247. Vandarkuzhali SA, Jeyalakshmi V, Sivaraman G, Singaravadivel S, Krishnamurthy KR, Viswanathan B. Highly fluorescent carbon dots from pseudo-stem of banana plant: applications as nanosensor and bio-imaging agents. Sens Actuators B 2017;252:894-900.

248. Zheng Y, Xie G, Zhang X, Chen Z, Cai Y, Yu W, et al. Bio-imaging application and growth promoting behaviour of carbon dots from pollen on hydroponically cultivated rome lettuce. ACS Omega 2017;2:3958-65.

249. RC Sanggo JE, Jin L, Diaz JMA, Guerrero RA, He J. Gram-scale synthesis and kinetic study of bright carbon dots from citric acid and citrus japonica via a microwave-assisted method. ACS Omega 2017;2:5196-208.

250. Huang G, Chen X, Wang C, Zheng H, Huang Z, Chen D, et al. Photoluminescent carbon dots derived from sugarcane molasses: synthesis, properties, and applications. RSC Adv 2017;7:47840-7.

251. Sun X, He J, Yang S, Zheng M, Wang Y, Ma S, et al. Green synthesis of carbon dots originated from lycii fructus for effective fluorescent sensing of ferric ion and multicolor cell imaging. J Photochem Photobiol B 2017;175:219-25.

252. Ensafi A, Kazemifard N, Rezaei B, Moradi F. A novel one-step and green synthesis of highly fluorescent carbon dots from saffron for cell imaging and sensing of prilocaine. Sens Actuators B 2017;253:451-60.

253. Liu W, Li C, Sun X, Pan W, Yu G, Wang J. Highly crystalline carbon dots from fresh tomato: UV emission and quantum confinement. Nanotechnology 2017;28:485705.

254. Liu Y, Zhou Q, Li J, Lei M, Yan X. Selective and sensitive chemosensor for lead ions using fluorescent carbon dots prepared from chocolate by one-step hydro-thermal method. Sens Actuators B 2016;237:597-604.

255. Zhao C, Jiao Y, Hu F, Yang Y. Green synthesis of carbon dots from pork and application as nanosensors for uric acid detection. Spectrochim Acta Part A 2018;190:360-7.
256. Zhang Q, Zhang N, Yang X, Chen H, Zhang B. Preparation of Au and $\mathrm{Au}$-carbon dots nanoparticles with sesbania gum as a reducing and stabilizing reagent. Dig J Nanomater Biostructures 2017;12:1011-20.

257. Cao L, Song X, Song Y, Bi J, Cong S, Yu C, et al. Fluorescent nanoparticles from mature vinegar: their properties and interaction with dopamine. Food Funct 2017;8:4744-51.

258. Zhai H, Zheng B, Yang F, Wang M, Xiao D. Synthesis of watersoluble flourescent carbon dots from setcreaseapurpurea boom and its application for $\mathrm{Br} 2$ detection. Anal Methods 2018;10:151-7.

259. Li L, Li L, Chen C, Cui F. Green synthesis of nitrogen doped carbon dots from ginkgo fruits, and the application in cell imaging. Inorg Chem Commun 2017;86:227-31.

260. Ren G, Tang M, Chai F, Wu H. One-pot synthesis of highly fluorescent carbon dots from spinach and multipurpose applications. Eur J Inorg Chem 2018;8:153-8.

261. Sim LC, Wong JL, Hak CH, Tai JY, Leong KH, Saravanan P. Sugarcane juice derived carbon degraphitic carbon nitride composites for bisphenol a degradation under sunlight irradiation. Beilstein J Nanotechnol 2018;9:353-63.

262. Ma X, Dong Y, Sun H, Chen N. Highly fluorescent carbon dots from peanut shells as potential probes for copper ion: the optimization and analysis of the synthetic process. Mater Today Chem 2017;5:1-10.

263. Bandi R, Dadigala R, Gangapuram BR, Guttena V. Green synthesis of highly fluorescent nitrogechoped carbon dots from lantana camara berries for effective detection of lead (II) and bioimaging. J Photochem Photobiol B 2018;178:330-8.

264. Vasimalai N, Vilas Boas V, Gallo J, de Fatima Cerqueira M, Menendez Miranda M, Costa Fernandez JM, et al. Green synthesis of fluorescent carbon dots from spices for in vitro imaging and tumour cell growth inhibition. Beilstein J Nanotechnol 2018;9:530-44.

265. Pal T, Mohiyuddin S, Packirisamy G. Facile and green synthesis of multicolor fluorescence carbon dots from curcumin: in vitro and in vivo bioimaging and other applications. ACS Omega 2018;3:831-43.

266. Li P, Hu Y. Turn-Off" fluorescent sensor for pamidronate disodium and zoledronic acid based on newly synthesized carbon dots from black tea. J Anal Methods Chem 2018;2018:1-7.

267. Lin F, Li C, Chen Z. Bacteria-derived carbon dots inhibit biofilm formation of Escherichia coli without affecting cell growth. Front Microbiol 2018;9:259.

268. Wang S, Wang H, Zhang R, Zhao L, Wu X, Xie H, et al. Egg yolkderived carbon: achieving excellent fluorescent carbon dots and high performance lithium-ion batteries. J Alloys Compd 2018;746:567-75.

269. D'souza SL, Chettiar SS, Koduru JR, Kailasa SK. Synthesis of fluorescent carbon dots using daucus carota subsp. sativus roots for mitomycin drug delivery. OPTIK 2018;158:893-900.

270. Ding H, Du F, Liu P, Chen Z, Shen J. DNAarbon dots function as fluorescent vehicles for drug delivery. ACS Appl Mater Interfaces 2015;7:6689-97.

271. Arul V, Sethuraman MG. Facile green synthesis of fluorescent ndoped carbon dots from actinidia deliciosa and their catalytic activity and cytotoxicity applications. Opt Mater 2018;78:181-90.

272. Miao H, Wang Y, Yang X. Carbon dots derived from tobacco for visually distinguishing and detecting three kinds of tetracyclines. Nanoscale 2018;10:8139-45.

273. Moradi S, Sadrjavadi K, Farhadian N, Hosseinzadeh L, Shahlaei M. Easy synthesis, characterization and cell cytotoxicity of green nano carbon dots using hydrothermal carbonization of gum tragacanth and chitosan bio-polymers for bioimaging. J Mol Liq 2018;259:284-90.

274. Xu Cheng F, Xuan Hua L, Jin J, Zhang J, Wei G. Facile synthesis of bagasse waste derived carbon dots for trace mercury detection. Mater Res Express 2018;5:0.065044.

275. Zheng M, Ruan SB, Liu S, Sun TT, Qu D, Zhao HF, et al. Selftargeting fluorescent carbon dots for diagnosis of brain cancer cells. ACS Nano 2015a;9:11455-60. 
276. Jia Q, Zheng X, Ge J, Liu W, Ren H, Chen S, et al. Synthesis of carbon dots from hypocrellabambusae for bimodel fluorescence/ photoacoustic imaging-guided synergistic photodynamic/photothermal therapy of cancer. J Colloid Interface Sci 2018;526:302-31.

277. Ahmadian Fard Fini S, Salavati Niasari M, Ghanbari D. Hydrothermal green synthesis of magnetic Fe304-carbon dots by lemon and grape fruit extracts and as a photo-luminescence sensor for detecting of E. coli bacteria. Spectrochim Acta Part A 2018;203:481-93.

278. Mishra V, Patil A, Thakur S, Kesharwani P. Carbon dots: emerging theranostic nanoarchitectures. Drug Discovery Today 2108;23:1219-32.

279. Teng X, Ma C, Ge C, Yan M, Yang J, Zhang Y, et al. Green synthesis of nitrogen-doped carbon dots from konjac flour with "offon" fluorescence by Fe3+and L-lysine for bioimaging. J Mater Chem B 2014;2:4631-9.

280. Mandal TK, Parvin N. Rapid detection of bacteria by carbon quantum dots. J Biomed Nanotechnol 2011;7:846-8.

281. Yang J, Zhang X, Ma YH, Gao G, Chen X, Jia HR, et al. Carbon dotbased platform for simultaneous bacterial distinguishment and antibacterial applications. ACS Appl Mater Interfaces 2016;8:32170-81.

282. Liu XJ, Zhang N, Bing T, Shangguan DH. Carbon dots based dualEmission silica nanoparticles as a ratiometric nanosensor for Cu2+. Anal Chem 2014a;86:2289-96.

283. Wu X, Sun S, Wang Y, Zhu J, Jiang K, Leng Y, et al. A fluorescent carbon dot-based mitochondria-targetable nanoprobe for peroxy nitrite sensing in living cells. Biosens Bioelectron 2017;90:501-7.

284. Tao H, Yang $\mathrm{K}, \mathrm{Ma} Z$, Wan J, Zhang Y, Kang Z, et al. In vivo NIR fluorescence imaging biodistribution, and toxicology of photoluminescent of carbon dots produced from carbon nanotubes and graphite. Small 2012;8:281-90.

285. Juzenas P, Kleinauskas A, Luo PG, Sun YP. Photoactivatable carbon for cancer therapy. Appl Phys Lett 2013;103:063701.

286. Li CF, Yan ZK, Chen L, Jin JP, Li DD. Desmin detection by facile prepared carbon quantum dots for early screening of colorectal cancer. Medicine 2017;96:e5521.

287. Parthiban V, Panda SK, Sahu AK. Highly fluorescent carbon quantum dots-Nafion as proton selective hybrid membrane for direct methanol fuel cells. Electrochim Acta 2018;292:855-64.

288. Sabet M, Mahdavi K. Green synthesis of high photoluminescence nitrogen-doped carbon quantum dots from grass via a simple hydrothermal method for removing organic and inorganic water pollutions. Appl Surf Sci 2019;463:283-91.

289. Arumugam N, Kim J. Synthesis of carbon quantum dots from Broccoli and their ability to detect silver ions. Mater Lett 2018;219:37-40.

290. Ramar V, Moothattu S, Balasubramanian K. Metal free, sunlight and white light based photocatalysis using carbon quantum dots from citrus grandis: a green way to remove pollution. Sol Energy 2018;169:120-7.

291. Qiang T, Han M, Wang X. Waterborne polyurethane/carbon quantum dot nanocomposite as a surface coating material exhibiting outstanding luminescent performance. Prog Org Coatings 2019;138:105433.

292. Kalaiyarasan G, Joseph J. Cholesterol derived carbon quantum dots as fluorescence probe for the specific detection of haemoglobin in diluted human blood samples. Mater Sci Eng C 2019;94:580-6.

293. Zhang Z, Wu L, Wang P, Zhang Y, Wan S, Guo X, et al. Carbon quantum dots modified La $2 \mathrm{Ti} 207$ nanosheets for visible light photocatalysis. Mater Lett 2018;230:72-5.

294. Jiang X, Qin D, Mo G, Feng J, Yu C, Mo W, et al. Ginkgo leaf-based synthesis of nitrogen-doped carbon quantum dots for highly sensitive detection of salazosulfa-pyridine in mouse plasma. J Pharm Biomed Anal 2019;164:514-9.

295. Athika M, Prasath A, Duraisamy E, Sankar Devi V, Selva Sharma A, Elumalai P. Carbon-quantum dots derived from denatured milk for efficient chromium-ion sensing and supercapacitor applications. Mater Lett 2019;241:156-9.

296. Aghamali A, Khosravi M, Hamishehkar H, Modirshahla N, Behnajady MA. Synthesis and characterization of high efficient photoluminescent sunlight driven photocatalyst of $\mathrm{N}$-carbon quantum dots. J Lumin 2018;201:265-74.

297. Algarra M, Gonzalez Calabuig A, Radotic K, Mutavdzic D, Ania CO, Lazaro-Martinez JM, et al. Enhanced electrochemical response of carbon quantum dot modified electrodes. Talanta 2018;178:679-85.

298. Wang Y, Cui Y, Zhao Y, He B, Shi X, Di D, et al. Fluorescent carbon dot-gated multifunctional mesoporous silica nanocarriers for redox/enzyme dual-responsive targeted and controlled drug delivery and real-time bioimaging. Eur J Pharm Biopharm 2018b;117:105-15.

299. Wang J, Li Q, Zhou JE, Wang Y, Yu L, Peng H, et al. Synthesis, characterization and cells and tissues imaging of carbon quantum dots. Opt Mater 2017a;72:15-9.

300. X Cai, X Li, Y Liu, G Wu, Y Zhao, F Chen, et al. Galactose decorated acidlabile nanoparticles encapsulating quantum dots for enhanced cellular uptake and subcellular localization. Pharm Res 2012;29:2167-79.

301. Souza DR, Caminhas LD, de Mesquita JP, Pereira FV. Luminescent carbon dots obtained from cellulose. Mater Chem Phys 2018;203:148-55.

302. Zhong Q, Chen Y, Su A, Wang Y. Synthesis of catalytically active carbon quantum dots and its application for colorimetric detection of glutathione. Sensors Actuators B Chem 2018;273:1098-102.

303. Shi Y, Liu X, Wang M, Huang J, Jiang X, Pang J, et al. Synthesis of $\mathrm{N}$-doped carbon quantum dots from bio-waste lignin for selective irons detection and cellular imaging. Int J Biol Macromol 2019;128:537-45.

304. Qiang T, Han M, Wang X. Waterborne polyurethane/carbon quantum dot nanocomposite as a surface coating material exhibiting outstanding luminescent performance. Prog Org Coatings 2019;138:105433.

305. Yang W, Yang H, Ding W, Zhang B, Zhang L, Wang L. High quantum yield $\mathrm{ZnO}$ quantum dots synthesizing via an ultrasonication microreactor method. Ultrason Sonochem 2016;33:106-17.

306. Sui Y, Wu L, Zhong S, Liu Q. Carbon quantum dots/TiO2 nanosheets with dominant facets for enhanced. Appl Surface Sci 2019;480:810-6.

307. Xie X, Yang Y, Xiao YH, Huang X, Shi Q, Zhang WD. Enhancement of photo-electrochemical activity of Fe2O3 nanowires decorated with carbon quantum dots. Int J Hydrogen Energy 2018;43:6954-62.

308. Saikia M, Hower JC, Das T, Dutta T, Saikia BK. Feasibility study of preparation of carbon quantum dots from Pennsylvania anthracite and Kentucky bituminous coals. Fuel 2019;243:433-40.

309. Arvind S, Mohapatra PK, Kalyanasundaram D, Kumar S. Selffunctionalized ultrastable water suspension of luminescent carbon quantum dots. Mater Chem Phys 2019;225:23-35.

310. Wang Q, Wang G, Liang X, Dong X, Zhang X. Supporting carbon quantum dots on NH2-MIL-125 for enhanced photocatalytic degradation of organic pollutants under a broad-spectrum irradiation. Appl Surf Sci 2019;467-468:320-7.

311. Che Y, Pang H, Li H, Yang L, Fu X, Liu S, et al. Microwave-assisted fabrication of copper-functionalized carbon quantum dots for sensitive detection of histidine. Talanta 2019;196:442-8.

312. Yang P, Zhu Z, Chen M, Chen W, Zhou X. Microwave-assisted synthesis of xylanderived carbon quantum dots for tetracycline sensing. Opt Mater (Amst) 2018;85:329-36.

313. Monte SS, Andrade SIE, Lima MB, Araujo MCU. Synthesis of highly fluorescent carbon dots from lemon and onion juices for determination of riboflavin in multivitamin/mineral supplements. J Pharm Anal 2019;9:209-16.

314. Joshi PN, Mathias A, Mishra A, Mathias A. Synthesis of ecofriendly fluorescent carbon dots and their biomedical and environmental applications. Mater Technol 2018;33:672-80.

315. Azizi B, Farhadi K, Samadi N. Functionalized carbon dots from zein biopolymer as a sensitive and selective fluorescent probe for determination of sumatriptan. Microchem J 2019;146:96573.

316. Bhattacharya S, Sarkar R, Chakraborty B, Porgador A, Jelinek R. Nitric oxide sensing through azo-dye formation on carbon dots. ACS Sens 2017;2:1215-24. 
317. Lu W, Gong X, Yang Z, Zhang Y, Hu Q, Shuang S, et al. High quality water-soluble luminescent carbon dots for multicolor patterning, sensors, and bioimaging. RSC Adv 2015;5:16972-9.

318. Yang J, He X, Chen L, Zhang Y. The selective detection of galactose based on boronic acid functionalized fuorescent carbon dots. Anal Methods 2016;8:8345-51.

319. Qian Z, Shan X, Chai L, Ma J, Chen J, Feng H. Si-doped carbon quantum dots: a facile and general preparation strategy, bioimaging application, and multifunctional sensor. ACS Appl Mater Interfaces 2014;6:6797-805.

320. Jiang Y, Wang Z, Dai Z. Preparation of silicon-carbon-based dots@ dopamine and its application in intracellular $\mathrm{Ag}+$ detection and cell imaging. ACS Appl Mater Interfaces 2016;8:3644-50.

321. Lan J, Liu C, Gao M, Huang C. An efcient solid-state synthesis of fuorescent surface carboxylated carbon dots derived from C60 as a label-free probe for iron ions in living cells. Talanta $2015 ; 144: 93-7$

322. Wu X, Tian F, Wang W, Chen J, Wu M, Zhao JX. Fabrication of highly fuorescent graphene quantum dots using l-glutamic acid for in vitro/in vivo imaging and sensing. J Mater Chem C 2013;1:4676-84.

323. Bhattacharya S, Sarkar R, Chakraborty B, Porgador A, Jelinek R. Nitric oxide sensing through azo-dye formation on carbon dots. ACS Sen 2017;2:1215-24.

324. Shan X, Chai L, Ma J, Qian Z, Chen J, Feng H. B-doped carbon quantum dots as a sensitive fluorescence probe for hydrogen peroxide and glucose detection. Analyst 2014;139:2322-5

325. Chen Z, Wang J, Miao H, Wang L, Wu S, Yang X. Fluorescent carbon dots derived from lactose for assaying folic acid. Sci China Chem 2015;59:487-92.

326. Chen J, Liu J, Li J, Xu L, Qiao Y. One-pot synthesis of nitrogen and sulfur co-doped carbon dots and its application for sensor and multicolor cellular imaging. J Colloid Interface Sci 2017;485:167-74.

327. Kaur N, Mehta A, Mishra A, Chaudhary S, Rawat M, Basu S. Amphiphilic carbon dots derived by cationic surfactant for selective and sensitive detection of metal ions. Mater Sci Eng C Mater Biol Appl 2018;95:72-7.

328. Pan X, Zhang Y, Sun X, Pan W, Wang J. A green emissive carbondotbased sensor with diverse responsive manners for multimode sensing. Analyst 2018;143:5812-21.

329. Zhang Y, Cui P, Zhang F, Feng X, Wang Y, Yang Y, et al. Fluorescent probes for "of-on" highly sensitive detection of $\mathrm{Hg} 2+$ and l-cysteine based on nitrogen-doped carbon dots. Talanta 2016;152:288-300.

330. Zhou M, Zhou Z, Gong A, Zhang Y, Li Q. Synthesis of highly photoluminescent carbon dots via citric acid and Tris for iron(III) ions sensors and bioimaging. Talanta 2015;143:107-13.

331. Che Y, Pang H, Li H, Yang L, Fu X, Liu S, et al. Microwave-assisted fabrication of copper-functionalized carbon quantum dots for sensitive detection of histidine. Talanta 2019;196:442-8.

332. Sui Y, Wu L, Zhong S, Liu Q. Carbon quantum dots/TiO2 nanosheets with dominant facets for enhanced photocatalytic hydrogen evolution. Appl Surf Sci 2019;480:810-6.

333. Azizi B, Farhadi K, Samadi N. Functionalized carbon dots from zein biopolymer as a sensitive and selective fluorescent probe for determination of sumatriptan. Microchem J 2019;146:965-73.

334. Yang P, Zhu Z, Chen M, Chen W, Zhou X. Microwave-assisted synthesis of xylan derived carbon quantum dots for tetracycline sensing. Opt Mater (Amst) 2018;85:329-36.

335. Azizi B, Farhadi K, Samadi N. Functionalized carbon dots from zein biopolymer as a sensitive and selective fluorescent probe for determination of sumatriptan. Microchem J 2019;146:965-73.

336. Wang Q, Wang G, Liang X, Dong X, Zhang X. Supporting carbon quantum dots on NH2-MIL-125 for enhanced photocatalytic degradation of organic pollutants under a broad-spectrum irradiation. Appl Surf Sci 2019;467-468:320-7.

337. Pan X, Zhang $Y$, Sun X, Pan W, Wang J. A green emissive carbondotbased sensor with diverse responsive manners for multimode sensing. Analyst 2018;143:5812-21.

338. Sun Y, Wang X, Wang C, Tong D, Wu Q, Jiang K, et al. Red emitting and highly stable carbon dots with dual response to pH values and ferric ions. Microchim Acta 2018;185:83.
339. Zhang J, Yan J, Wang Y, Zhang Y. One-step hydrothermal approach to synthesis carbon dots from d-sorbitol for detection of iron(III) and cell imaging. J Nanosci Nanotechnol 2018;18:4457-63.

340. Zhang Y, Cui P, Zhang F, Feng X, Wang Y, Yang Y, et al. Fluorescent probes for "of-on" highly sensitive detection of $\mathrm{Hg}^{2+}$ and l-cysteine based on nitrogen-doped carbon dots. Talanta 2016;152:288-300.

341. Chen J, Liu J, Li J, Xu L, Qiao Y. One-pot synthesis of nitrogen and sulfur co-doped carbon dots and its application for sensor and multicolor cellular imaging. J Colloid Interface Sci 2017;485:167-74.

342. Chen Z, Wang J, Miao H, Wang L, Wu S, Yang X. Fluorescent carbon dots derived from lactose for assaying folic acid. Sci China Chem 2015;59:487-92.

343. Li J Y, Liu Y, Shu QW, Liang JM, Zhang F, Chen XP, et al. One-pot hydrothermal synthesis of carbon dots with efcient up-and down-converted photoluminescence for the sensitive detection of morin in a dual-readout assay. Langmuir 2017;33:1043-50.

344. Bhattacharya S, Sarkar R, Chakraborty B, Porgador A, Jelinek R. Nitric oxide sensing through azo-dye formation on carbon dots. ACS Sen 2017;2:1215-24.

345. Qin Z, Wang W, Zhan X, Du X, Zhang Q, Zhang R, et al. One pot synthesis of dual carbon dots using only an $\mathrm{N}$ and $\mathrm{S}$ coexisted dopant for fluorescence detection of Ag+. Spectrochim Acta A Mol Biomol Spectrosc 2019;5:162-71.

346. Lan J, Liu C, Gao M, Huang C. An efficient solid-state synthesis of fluorescent surface carboxylated carbon dots derived from C60 as a label-free probe for iron ions in living cells. Talanta 2015;144:93-7.

347. Xu Q, Su R, Chen Y, Sreenivasan ST, Li N, Zheng X, et al. Metal charge transfer doped carbon dots with reversibly switchable, ultra-high quantum yield photoluminescence. J Colloid Interface Sci 2018;1:1886-9.

348. Wu X, Tian F, Wang W, Chen J, Wu M, Zhao JX. Fabrication of highly fuorescent graphene quantum dots using l-glutamic acid for in vitro/in vivo imaging and sensing. J Mater Chem C 2013;1:4676-84.

349. Yang J, He X, Chen L, Zhang Y. The selective detection of galactose based on boronic acid functionalized fluorescent carbon dots. Anal Methods 2016;8:8345-51.

350. Zhou L, Lin Y, Huang Z, Ren J, Qu X. Carbon nanodots as fuorescence probes for rapid, sensitive, and label-free detection of $\mathrm{Hg} 2+$ and biothiols in complex matrices. Chem Commun 2012;48:1147-9.

351. Devi P, Thakur A, Chopra S, Kaur N, Kumar P, Singh N, et al. Ultrasensitive and selective sensing of selenium using nitrogenrich ligand interfaced carbon quantum dots. ACS Appl Mater Interfaces 2017;9:13448-56.

352. Miao X, Yan X, Qu D, Li D, Tao F, Sun Z. Red emissive sulfur, nitrogen codoped carbon dots and their application in ion detection and theranostics. ACS Appl Mater Interfaces 2017;9:18549-56.

353. Kaur N, Mehta A, Mishra A, Chaudhary S, Rawat M, Basu S. Amphiphilic carbon dots derived by cationic surfactant for selective and sensitive detection of metal ions. Mater Sci Eng C Mater Biol Appl 2018;95:72-7.

354. P Xu, J Li, L Shi, MB Selke, X Chen, Wang. Synergetic effect of functional cadmium-tellurium quantum dots conjugated with gambogic acid for HepG2 cell- labeling and proliferation inhibition. Int J Nanomed 2013;8:3729.

355. Sun T, Zheng M, Xie Z, Jing X. Supramolecular hybrids of carbon dots with doxorubicin: synthesis, stability and cellular trafcking. Mater Chem Front 2017;1:354-60.

356. Qian Z, Shan X, Chai L, Ma J, Chen J, Feng H. Si-doped carbon quantum dots: a facile and general preparation strategy, bioimaging application, and multifunctional sensor. ACS Appl Mater Interfaces 2014;6:6797-805.

357. Kaur N, Mehta A, Mishra A, Chaudhary S, Rawat M, Basu S. Amphiphilic carbon dots derived by cationic surfactant for selective and sensitive detection of metal ions. Mater Sci Eng C Mater Biol Appl 2018;95:72-7.

358. Shan X, Chai L, Ma J, Qian Z, Chen J, Feng H. B-doped carbon quantum dots as a sensitive fluorescence probe for hydrogen peroxide and glucose detection. Analyst 2014;139:2322-5. 
359. Jiang Y, Wang Z, Dai Z. Preparation of silicon-carbon-based dots at dopamine and its application in intracellular Ag+detection and cell imaging. ACS Appl Mater Interfaces. 2016;8:3644-50.

360. Jijie R, Barras A, Bouckaert J, Dumitrascu N, Szunerits S, Boukherroub R. Enhanced antibacterial activity of carbon dots functionalized with ampicillin combined with visible light triggered photodynamic effects. Colloid Surface B 2018;170:347-54.

361. Liu JJ, Lu SY, Tang QL, Zhang K, Yu WX, Sun HC, et al. One-step hydrothermal synthesis of photoluminescent carbon nanodots with selective antibacterial activity against porphyromonas gingivalis. Nanoscale 2017;9:7135-42.

362. Xiang Y, Mao C, Liu X, Cui Z, Jing D, Yang X, et al. Rapid and superior bacteria killing of carbon quantum Dots/ZnO decorated injectable folic acid-conjugated PDA hydrogel through dual-light triggered ROS and membrane permeability. Small 2019;15:e1900322.

363. Dong X, Moyer MM, Yang F, Sun YP, Yang L. Carbon dots' antiviral functions against noroviruses. Sci Rep 2017;7:519.

364. Yan YY, Kuang WC, Shi LJ, Ye XL, Yang YH, Xie XB, et al. Carbon quantum dot-decorated $\mathrm{TiO} 2$ for fast and sustainable antibacterial properties under visible-light. J Alloy Compd 2019;777:234-43.

365. Yang J, Zhang X, Ma YH, Gao G, Chen X, Jia HR, et al. Carbon dotbased platform for simultaneous bacterial distinguishment and antibacterial applications. Acs Appl Mater Inter 2016;8:32170-81.

366. Yang J. One-step synthesis of carbon dots with bacterial contact-enhanced fluorescence emission: fast gram-type identification and selective gram-positive bacterial inactivation. Carbon 2019;146:827-39.

367. Kovacova M, Markovic ZM, Humpolicek P, Micusik M, Svajdlenkova A. Carbon quantum dots modified polyurethane nanocomposite as effective photocatalytic and antibacterial agents. Acs Biomater Sci Eng 2018;4:3983-93.

368. Sidhu JS. The photochemical degradation of bacterial cell wall using penicillin-based carbon dots: weapons against multi-drug resistant (MDR) strains. Chem Select 2017;2:9277-83.

369. Li YJ, Harroun SG, Su YC, Huang CF, Unnikrishnan B, Lin HJ, et al. Synthesis of self-assembled spermidine-carbon quantum dots effective against multidrug-resistant bacteria. Adv Healthc Mater 2016;5:2545-54.

370. Zhang JT, Liu X, Wang XY, Mu LL, Yuan MM, Liu BK, et al. Carbon dots-decorated $\mathrm{Na}_{2} \mathrm{~W}_{4} \mathrm{O}_{13}$ composite with WO3 for highly efficient photocatalytic antibacterial activity. J Hazard Mater 2018;359:1-8.

371. Dong XL, Al Awak M, Tomlinson N, Tang YG, Sun YP, Yang LJ. Antibacterial effects of carbon dots in combination with other antimicrobial reagents. Plos One. 2017;12:0185324.

372. Du T, Liang JG, Dong N, Liu L, Fang LR, Xiao SB, et al. Carbon dots as inhibitors of virus by activation of type I interferon response. Carbon 2016;110:278-85.

373. Hirlekar R, Yamagar M, Garse H, Mohit VIJ, Kadam V. Carbon nanotubes and its application: a review. Asian J Pharm Clin Res 2009;2:17-27

374. Hou P, Yang T, Liu H, Li YF, Huang CZ. An active structure preservation method for developing functional graphitic carbon dots as an effective antibacterial agent and a sensitive pH and Al(III) nanosensor. Nanoscale 2017;9:17334-41.

375. Abu Rabe DI, Al Awak MM, Yang F, Okonjo PA, Dong XL, Teisl LR, et al. The dominant role of surface functionalization in carbon dots' photo-activated antibacterial activity. Int J Nanomed 2019;14:2655-65.

376. Huang SM, Gu JJ, Ye J, Fang B, Wan SF, Wang CY, et al. Benzoxazine monomer derived carbon dots as a broadspectrum agent to block viral infectivity. J Colloid Interf Sci 2019;542:198-206.

377. Priyadarshini E, Rawat K, Prasad T, Bohidar HB. Antifungal efficacy of $\mathrm{Au} @$ carbon dots nanoconjugates against opportunistic fungal pathogen, Candida albicans. Colloid Surface B 2018;163:355-61.

378. Li H, Huang J, Song YX, Zhang ML, Wang HB, Lu F, et al. Degradable carbon dots with broad-spectrum antibacterial activity. Acs Appl Mater Inter 2018;10:26936-46.
379. Manivannan R. Nanotechnology: a review. J Appl Pharm Sci 2011;1:8-16.

380. Liu C, Zhang P, Zhai X, Tian F, Li W, Yang J, et al. Nanocarrier for gene delivery and bioimaging based on carbon dots with PEI passivation enhanced fluorescence. Biomaterials 2012;33:3604-13.

381. Hsu PC, Chang HT. Synthesis of high-quality carbon nanodots from hydrophilic compounds: role of functional groups. Chem Commun 2012;48:3984-6.

382. Parvin N, Mandal TK. Dually emissive P, N-co-doped carbon dots for fluorescent and photoacoustic tissue-imaging in living mice. Microchim Acta 2017;184:1117-2.

383. Lai CW, Hsiao YH, Peng YK, Chou PT. Facile synthesis of highly emissive carbon dots from pyrolysis of glycerol gram scale production of carbon dots $/ \mathrm{mSiO} 2$ for cell imaging and drug release. J Mater Chem 2012;22:14403-9.

384. Sun Y, Wang S, Li C, Luo P, Tao L, Wei Y, et al. Large scale preparation of graphene quantum dots from graphite with tunable fluorescence properties. Phys Chem Chem Phys 2013;15:9907-13.

385. Yang W, Zhang H, Lai J, Peng X, Hu Y, Gu W, et al. Carbon dots with red-shifted photoluminescence by fluorine doping for optical bioimaging. Carbon 2018;128:78-85.

386. Hu C, Liu Y, Yang Y, Cui J, Huang Z, Wang Y, et al. One-step preparation of nitrogen-doped graphene quantum dots from oxidized debris of graphene oxide. J Mater Chem B 2013;1:39-42.

387. Krishna AS, Radhakumary C, Sreenivasan K. Detection and imaging of fatty plaques in blood vessels using functionalized carbon dots. Anal Methods 2015;7:9482-8.

388. Wang L, Yin Y, Jain A, Zhou HS. Aqueous-phase synthesis of highly luminescent, nitrogen-doped carbon dots and their application as bioimaging agents. Langmuir 2014;30:14270-5.

389. Photostable, biocompatible nitrogen-doped graphene quantum dots for cellular and deep-tissue imaging. Nano Lett 2013;13:2436-41.

390. Zhou L, Geng J, Liu B. Graphene quantum dots from polycyclic aromatic hydrocarbon for bioimaging and sensing of Fe3+and hydrogen peroxide. Part Part Syst Charact 2013;30:1086-92.

391. Zhu S, Zhang J, Qiao C, Tang S, Li Y, Yuan W, et al. Strongly green-photoluminescent graphene quantum dots for bioimaging applications. Chem Commun 2011;47:6858-60.

392. Dong Y, Chen C, Zheng X, Gao L, Cui Z, Yang H, et al. One-step and high yield simultaneous preparation of single-and multilayer graphene quantum dots from CX-72 carbon black. J Mater Chem 2012;22:8764-6.

393. Wang F, Xie Z, Zhang H, Liu CY, Zhang YG. Highly luminescent organo silane-functionalized carbon dots. Adv Funct Mater 2011;21:1027-31.

394. Zhang M, Bai L, Shang W, Xie W, Ma H, Fu Y, et al. Facile synthesis of water-soluble, highly fuorescent graphene quantum dots as a robust biological label for stem cells. J Mater Chem 2012;22:7461-7.

395. Qiao ZA, Wang Y, Gao Y, Li H, Dai T, Liu Y, et al. Commercially activated carbon as the source for producing multicolor photoluminescent carbon dots by chemical oxidation. Chem Commun 2010;46:8812-4.

396. Tao H, Yang K, Ma Z, Wan J, Zhang Y, Kang Z, et al. In vivo NIR fuorescence imaging, biodistribution, and toxicology of photoluminescent carbon dots produced from carbon nanotubes and graphite. Small 2012;8:281-90.

397. Peng J, Gao W, Gupta BK, Liu Z, Romero-Aburto R, Ge L, et al. Graphene quantum dots derived from carbon fbers. Nano Lett 2012;12:844-9.

398. Yang ZC, Wang M, Yong AM, Wong SY, Zhang XH, Tan H, et al. Intrinsically fluorescent carbon dots with tunable emission derived from hydrothermal treatment of glucose in the presence of monopotassium phosphate. Chem Commun 2011;47:11615-7.

399. Bhattacharya S, Sarkar R, Chakraborty B, Porgador A, Jelinek R. Nitric oxide sensing through azo-dye formation on carbon dots. ACS Sens 2017;2:1215-24.

400. Jiang Y, Wang Z, Dai Z. Preparation of silicon-carbon-based dots@ dopamine and its pplication in intracellular Ag+detection and cell imaging. ACS Appl Mater Interfaces 2016;8:3644-50. 
401. Lu W, Gong X, Yang Z, Zhang Y, Hu Q, Shuang S, et al. High quality water-soluble luminescent carbon dots for multicolor patterning, sensors, and bioimaging. RSC Adv 2015;5:16972-9.

402. Shan X, Chai L, Ma J, Qian Z, Chen J, Feng H. B-doped carbon quantum dots as a sensitive fuorescence probe for hydrogen peroxide and glucose detection. Analyst 2014;139:2322-5.

403. Chen Z, Wang J, Miao H, Wang L, Wu S, Yang X. Fluorescent carbon dots derived from lactose for assaying folic acid. Sci China Chem 2015;59:487-92.

404. Lan J, Liu C, Gao M, Huang C. An efficient solid-state synthesis of fluorescent surface carboxylated carbon dots derived from C60 as a label-free probe for iron ions in living cells. Talanta 2015;144:93-7.

405. Zhou L, Lin Y, Huang Z, Ren J, Qu X. Carbon nanodots as fuorescence probes for rapid, sensitive, and label-free detection of $\mathrm{Hg} 2+$ and biothiols in complex matrices. Chem Commun 2012;48:1147-9.

406. Yang J, He X, Chen L, Zhang Y. The selective detection of galactosebased on boronic acid functionalized fuorescent carbon dots. Anal Methods 2016;8:8345-5.

407. Zhang M, Zhao X, Fang Z, Niu Y, Lou J, Wu Y, et al. Fabrication of HA/PEI-functionalized carbon dots for tumor targeting, intracellular imaging and gene delivery. RSC Adv 2017;7:3369. 75.

408. Deng W, Fu M, Cao Y, Cao X, Wang M, Yang Y, Qu R, et al. Angelica sinensis polysaccharide nanoparticles as novel nonviral carriers for gene delivery to mesenchymal stem cells. Nanomed Nanotechnol Biol Med 2013;9:1181-91.

409. Qian Z, Shan X, Chai L, Ma J, Chen J, Feng H. Si-doped carbon quantum dots: a facile and general preparation strategy, bioimaging application, and multifunctional sensor. ACS Appl Mater Interfaces 2014;6:6797-805.

410. Wu X, Tian F, Wang W, Chen J, Wu M, Zhao JX. Fabrication of highly fuorescent graphene quantum dots using l-glutamic acid for in vitro/in vivo imaging and sensing. J Mater Chem $\mathrm{C}$ 2013;1:4676-84.

411. Qin J, Zhang LM, Yang R. Powder carbonization to synthesize novel carbon dots derived from uric acid for the detection of $\mathrm{Ag}(\mathrm{I})$ and glutathione. Spectrochim Acta Part A Mol Biomol Spectrosc 2019;207:54-60.

412. Guo Y, Wang Z, Shao H, Jiang X. Hydrothermal synthesis of highly fuorescent carbon nanoparticles from sodium citrate and their use for the detection of mercury ions. Carbon 2013;52:583-9.

413. Pan X, Zhang Y, Sun X, Pan W, Wang J. A green emissive carbondotbased sensor with diverse responsive manners for multimode sensing. Analyst 2018;143:5812-21.

414. Zhang Y, Cui $\mathrm{P}$, Zhang F, Feng X, Wang Y, Yang Y, et al. Fluorescent probes for "of-on" highly sensitive detection of
$\mathrm{Hg} 2+$ and l-cysteine based on nitrogen-doped carbon dots. Talanta 2016;152:288-300.

415. Zhang J, Yan J, Wang Y, Zhang Y. One-step hydrothermal approach to synthesis carbon dots from d-sorbitol for detection of iron(III) and cell imaging. J Nanosci Nanotechnol 2018;18:4457-63.

416. Wu J, Feng Y, Shao Y, Sun Y. High quality nitrogen and silicon co-doped carbon dots (N/Si-CDs) for Fe3+sensing. J Nanosci Nanotechnol 2018;18:4196-203.

417. Hu S, Zhao Q, Chang Q, Yang J, Liu J. Enhanced performance of Fe3p detection via fluorescence resonance energy transfer between carbon quantum dots and Rhodamine B. RSC Adv 2014;4:41069-75.

418. Ren G, Zhang Q, Li S, Fu S, Chai F, Wang C, et al. One pot synthesis of highly fluorescent $\mathrm{N}$ doped C-dots and used as fluorescent probe detection for $\mathrm{Hg} 2+$ and $\mathrm{Ag}+\mathrm{in}$ aqueous solution. Sens Actuators B Chem 2017;243:244-53.

419. Li Z, Yu H, Bian T, Zhao Y, Zhou C, Shang L, et al. Highly luminescent nitrogen-doped carbon quantum dots as effective fluorescent probes for mercuric and iodide ions. J Mater Chem C 2015;3:1922-8.

420. Zhou L, Lin Y, Huang Z, Ren J, Qu X. Carbon nanodots as fluorescence probes for rapid, sensitive, and label-free detection of $\mathrm{Hg} 2+$ and bio thiols in complex matrices. Chem Commun 2012;48:1147-9.

421. Zhang YL, Wang L, Zhang HC, Liu Y, Wang HY, Kang ZH, et al. Graphitic carbon quantum dots as a fluorescent sensing platform for highly efficient detection of Fe3p ions. RSC Adv 2013;3:3733-8.

422. Qian Z, Ma J, Shan X, Feng H, Shao L, Chen J. Highly luminescent $\mathrm{N}$-doped carbon quantum dots as an effective multifunctional fluorescence sensing platform. Chemistry 2014;20:2254-63.

423. Yang K, Li F, Che W, Hu X, Liu C, Tian F. Increment of the FRET efciency between carbon dots and photosensitizers for enhanced photodynamic therapy. RSC Adv 2016;6:101447-51.

424. Hassan M, Gomes VG, Dehghani A, Ardekani SM. Engineering carbon quantum dots for photo mediated theranostics. Nano Res 2018;1:1-41.

425. Hua XW, Bao YW, Wu FG. Fluorescent carbon quantum dots with intrinsic nucleolus-targeting capability for nucleolus imaging and enhanced cytosolic and nuclear drug delivery. ACS Appl Mater Interfaces 2018;10:10664-77.

426. Ge J, Jia Q, Liu W, Guo L, Liu Q, Lan M, et al. Red-emissive carbon dots for fluorescent, photoacoustic, and thermal theranostics in living mice. Adv Mater 2015;28:4169-77.

427. Zheng M, Li Y, Liu S, Wang W, Xie Z, Jing X. One-pot to synthesize multifunctional carbon dots for near-infrared fuorescence imaging and photothermal cancer therapy. ACS Appl Mater Interfaces 2016;8:23533-41. 